ESTRATÉGIA 


\title{
ORIENTAÇÃO EMPREENDEDORA: UMA ANÁLISE BIBLIOMÉTRICA EM PERIÓDICOS NACIONAIS E INTERNACIONAIS
}

\author{
ENTREPRENEURIAL ORIENTATION: A BIBLIOMETRIC IN JOURNALS NATIONAL \\ AND INTERNATIONAL
}

Bruno Ribas Silveira

Universidade Federal de Pelotas

Elvis Silveira-Martins

Universidade Federal de Pelotas
Data de submissão: 25 fev. 2016. Data de aprovação:

05 ago. 2016. Sistema de avaliação: Double blind review.

Universidade FUMEC / FACE. Prof. Dr. Henrique Cordeiro

Martins. Prof. Dr. Cid Gonçalves Filho. Prof. Dr. Luiz Claudio

Vieira de Oliveira

\section{RESUMO}

A orientação empreendedora $(\mathrm{OE})$ é fonte de análise das estratégias formuladas pelos tomadores de decisões em relação ao empreendedorismo. Neste contexto, objetiva-se nesta pesquisa contribuir com pesquisadores e gestores mapeando as pesquisas científicas sobre orientação empreendedora publicadas nos periódicos nacionais e internacionais. $\mathrm{O}$ procedimento metodológico alicerçou-se na técnica de pesquisa bibliométrica - exploratória e descritiva. Foram identificados 350 artigos, sendo que após a aplicação dos filtros metodológicos, II 2 foram analisados, compreendendo um espaço temporal entre 2003 e 2015 . Os dados foram analisados com o auxílio dos softwares, Excel, UCINET e NetDraw. O periódico Entrepreneurship Theory and Practice destaca-se com o maior número de trabalhos publicados sobre $\mathrm{OE}$. As redes de pesquisa com maior número de laços é a composta por William Wales e pelas instituições Ball State University e Lulea Univeristy of Technology. $O$ autor mais citado é Covin, ainda que o trabalho mais citado é de Lumpkin e Dess.

\section{PALAVRAS-CHAVE}

Orientação Empreeendedora. Bibliometria. Estratégia. Empresas. 


\section{ABSTRACT}

The entrepreneurial orientation (EO) is a source of analysis of the strategies formulated by decision makers towards entrepreneurship. In this context, the objective of this research contribute to researchers and managers mapping scientific research on entrepreneurial orientation published in national and international journals. The methodological procedure its foundations in the bibliometric research technique - exploratory and descriptive. 350 articles were identified, and after the application of the methodological filters, I I 2 were analyzed, including a timeline from 2003 to 2015. The data were analyzed with the help of software, Excel, and UCINET NetDraw.The journal Entrepreneurship Theory and Practice stands out with the largest number of published works on $O E$. Research networks with the highest number of bonds is comprised of William Wales and institutions Ball State University and Lulea Univeristy of Technology. The most cited author is Covin, however, the most cited work is Lumpkin and Dess.

\section{KEYWORDS}

Entrepreneurial Orientation. Performance. Bibliometrics. Strategy. Business.

\section{INTRODUÇÃO}

A permanente busca pelo crescimento das organizações atrai o interesse da academia, que tenta explicar de que forma o empreendedorismo impacta no desenvolvimento sustentável da empresa, criando vantagens competitivas. Diante desse contexto, pesquisas sobre a orientação empreendedora (OE) têm ganhado força nas últimas três décadas, sendo alvo de agendas de cientistas da área de estratégia e de tomadores de decisões, interessados em entender as múltiplas facetas (desdobramentos diretos e indiretos) desse construto.

A constante influência do ambiente no contexto organizacional exige que os gestores tenham uma atuação proativa para que possam gerir seus recursos da melhor forma possível, identificando oportunidades, ameaças e tendências do mercado em que atuam. Nesse cenário,
Lumpkin e Dess (1996) relatam que a OE surge como um processo estratégico que fornece bases necessárias para a tomada de decisões.

Assim, o conceito de OE é importante para qualquer empresa, independentemente do seu tipo ou tamanho (KNIGHT, 1997; SILVEIRA-MARTINS; VAZ, 20I6), uma vez que a mesma encontra respaldo em resultados de diversas pesquisas que afirmam que a mesma é um fenômeno preditivo no desempenho organizacional (LUMPKIN; DESS, 1996; HUGGINS;THOMPSON, 20I5).

Desse modo, o objetivo da presente pesquisa é mapear as publicações científicas sobre orientação empreendedora publicadas nos periódicos nacionais e internacionais no período de 2003 a 2015, descrevendo as principais características no campo do construto e seus relacionamentos.

Considerando a relevância da $\mathrm{OE}$ no 
contexto organizacional, e do crescente interesse por pesquisadores em relação ao tema, o objetivo de pesquisa justifica-se na ausência, ou não identificação, de uma análise da produção científica nacional e internacional em periódicos classificados pelo Qualis-Capes (AI $\longmapsto$ B2) e com fator de impacto. Esses critérios foram considerados em função dos critérios utilizados para pelo Conselho Nacional de Desenvolvimento Científico e Tecnológico (ex. chamada MCTI/CNPq n 24/20 I5), Coordenação de Aperfeiçoamento de Pessoal de Nível Superior e outras fundações estaduais, a exemplo da Fundação de Amparo à Pesquisas do Estado do Rio Grande do Sul (ex. edital Fapergs 04/2014) para qualificar-se ao pleito de recursos para a editoração e publicação de obras científicas, embora esses não sejam os únicos critérios. Quanto ao fator de impacto, justifica-se em função da credibilidade internacional conferida aos mesmos.

A pesquisa será apresentada considerando, além dessa introdução, outras cinco seções. Desta maneira, na segunda seção serão apresentados os principais conceitos envolvendo o construto orientação empreendedora. $\mathrm{Na}$ sequência, será delineada a metodologia que foi aplicada para o alcance do objetivo proposto. $\mathrm{Na}$ quarta seção, os dados coletados serão, com base nos procedimentos metodológicos, analisados. A quinta seção apresenta as conclusões sobre a pesquisa, suas limitações e sugestões para estudos futuros. Por fim, são apresentadas as referências utilizadas no desenvolvimento da pesquisa.

\section{REFERENCIAL TEÓRICO}

Nesta seção, serão apresentados os conceitos teóricos que suportam o cons- truto orientação empreendedora e suas dimensões: i) inovatividade, ii) proatividade, iii) assunção de riscos, iv) autonomia, v) agressividade ou competitividade, vi) redes de negócios ou de relações.

\section{Orientação empreendedora}

O conceito de orientação empreendedora (OE), em nível organizacional, é encontrado na literatura sobre estratégia e empreendedorismo, cuja origem remota está nos estudos de Miller (1983). Porém, as raízes da pesquisa em $O E$ podem ser atribuídas ao trabalho de Mintzberg (1973), em que se teorizou sobre a tomada de decisão estratégica empresarial como uma disposição gerencial caracterizada pela procura de diferentes oportunidades em ambientes incertos, através de que o crescimento poderia ser alcançado.

Não obstante, Miller (1983) reconhece a importância do líder, do sujeito que empreende, porém acrescenta o papel da estrutura organizacional e a importância da construção da estratégia, concentrando esforços na ênfase das capacidades inovadoras das atividades empreendedora da organização. Conforme o autor, a OE é concebida como sendo o comportamento que permite que a empresa seja empreendedora, baseando-se em três dimensões: inovação, proatividade e assunção de riscos.

Segundo Covin e Slevin (1991), a OE apresenta uma grande influência sobre o desempenho organizacional, sendo uma das mais importantes fontes de vantagem competitiva. Posteriormente, muitos outros estudos indicaram a relação positiva entre orientação empreendedora e desempenho organizacional (ZAHRA, I993; ZAHRA; COVIN, 1995; WIKLUND, 1999; HEELEY, 2000; COVIN et al., 2006; TANG; TANG; 
ZHANG et al., 2007; GREEN; COVIN; SLEVIN, 2008; MILES; COVIN;WANG, 2008).

De acordo com Lumpkin e Dess (1996), a orientação empreendedora reporta-se aos métodos, práticas e estilo de tomada de decisão gerencial empregados para agir de maneira empreendedora, permitindo que diferentes oportunidades de negócios sejam criadas com êxito, de forma intencional, envolvendo atitudes de pessoas centrais em um processo dinâmico.

Em complemento a esse pensamento, Knight (1997) destaca que a orientação empreendedora possibilita que as empresas consigam ampliar suas capacidades aumentando seus limites, fortalecendo assim a gestão de seus recursos.

Por outra ótica, Hitt et al. (1999) contextualiza que as organizações com forte OE possuem uma maior aptidão em lidar com incertezas do ambiente em seu benefício. Todos os níveis organizacionais de uma empresa são atingidos por organizações que buscam obter uma eficiente $O E$, refletindo em práticas gerenciais bem desenvolvidas e também moldando a forma de atuação para um estilo mais empreendedor (STEVENSON; JARILLO, 1990; COVIN; SLEVIN, I99I).

Tendo em vista $\circ$ interesse de pesquisadores na temática orientação empreendedora, muitas são as definições, sobre o construto, que foram disseminadas desde os estudos iniciais. Assim, no Quadro I, pode-se verificar uma compilação de alguns desses conceitos/definições.

Lumpkin e Dess (1996) relatam que o efeito da relação entre $\mathrm{OE}$ e desempenho pode ser melhor compreendido, considerando a inclusão de outras duas dimensões: autonomia e agressividade competitiva, sendo que estas devem ser analisadas como complementares às que foram propostas por Miller (1983). Para os autores, a relevância de cada dimensão para estimar o êxito de um negócio depende de fatores externos, fatores internos, ou, ainda, de particularidades dos fundadores ou dos líderes da organização, podendo a OE ser formada por diferentes combinações entre as dimensões, ou até mesmo por apenas algumas delas.

Mais recentemente, outra dimensão foi identificada nos estudos de Mello e Leão (2005), que se traduz no comportamento empreendedor de criar redes de negócios ou de relações, na medida em que a construção de relacionamentos torna-se indispensável para o ingresso em novos mercados e internacionalização dos negócios.

Embora a construção da OE tenha sido utilizada em diversas literaturas, sua definição e medição geraram um debate considerável. Alguns pesquisadores abordam as preocupações que existem sobre as dimensionalidades e mensurações. Em alguns casos, os pesquisadores concentramse em apenas uma dimensão e eliminam as demais. Assim, as questões de mensuração são particularmente problemáticas em um contexto internacional, devido às diferenças culturais e institucionais que podem influenciar a formação e incidência de comportamentos empresariais (ZAHRA, 1993; KNIGHT, 1997; DESS et al., 1999; LUMPKIN; DESS, 200I; KREISER et al., 2002; ZHENG ZHOU et al., 2005).

Diante desse contexto, verifica-se que são empregadas abordagens diferentes para a análise da OE. Assim, verifica-se no Quadro 2 a contribuição de Martens; Freitas e Andres (20I I) para o entendimento dos posicionamentos, com a apresentação das pesquisas e as dimensões utilizadas. 
QUADRO 1 - Definições da orientação empreendedora

\begin{tabular}{|c|c|}
\hline Autores & Definição $\mathrm{OE}$ \\
\hline Mintzberg (1973) & $\begin{array}{l}\text { "No modo empresarial, a tomada de decisão es tratégicaé dominada pela busca } \\
\text { ativa de novas oportunidades", bem como " saltos dramáticos parafrente em face } \\
\text { da incerteza" (p. } 45 \text { ). }\end{array}$ \\
\hline Khandwalla $(1976 / 1977)$ & $\begin{array}{l}\text { "O estilo empresarial (gestăo) é caracterizado pela tomada de decisăo ou sada, } \\
\text { arriscada e agressiva (p. } 25 \text { )". }\end{array}$ \\
\hline Miller e Friesen (1982) & $\begin{array}{l}\text { "O modelo empresarial se aplica empresas que inovam regulamente e com } \\
\text { ousadia, enquanto tomam riscos consideráveis em suas estratégias de produto- } \\
\text { mercado (p. 5)". }\end{array}$ \\
\hline Miller (1983) & 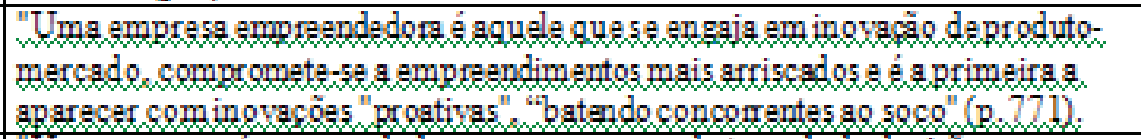 \\
\hline Morris e Paul (1987) & $\begin{array}{l}\text { "Ua empresa é empreendedora com as nomas de tomada de decisăo que } \\
\text { enfatizam es tratégias proativas e inovadoras que contêmum elemento derisco" } \\
\text { (p. 249). }\end{array}$ \\
\hline Coxin e Slexi & $\begin{array}{l}\text { "Empresas empreendedoras săo aquelas em que os gestores de topo têm estilos de } \\
\text { gestão empresarial. Evidenciado por decisões estratégicas das empresas e } \\
\text { filos ofias de gestâo operacional. Empresas não empreandedoras ou conservadoras } \\
\text { são aquelas em que o estilo de gestão de topo é decididamente avessos a risco, } \\
\text { hão-inovadgras, pas sivas ou reativas" (p. 218). }\end{array}$ \\
\hline Merz e Sayl & $\begin{array}{l}\text {. orientaçào empreendedora é definida como o grau de proatividada } \\
\text { (agres sividade) da empresae sua vontade de inovare criar novas ofertas " (p. 554). }\end{array}$ \\
\hline Lumpkin e Das & 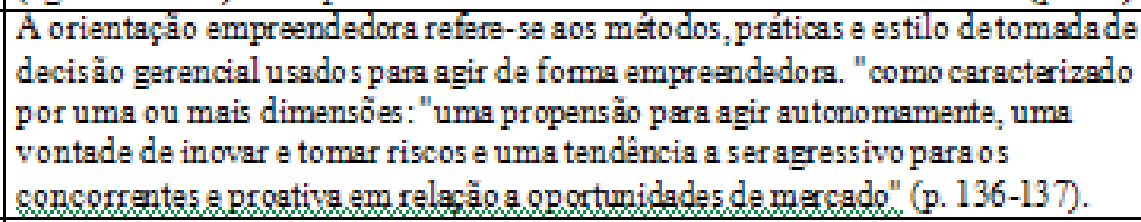 \\
\hline Zahra e Neubs & $\begin{array}{l}\text { OE é "a soma total de inovaçóes radicais de uma empresa, a ação es tratégica } \\
\text { proativa, e de as sumir riscos e atividades que se manifestam em apoio a projetos } \\
\text { com resultados incertos" (p. 124). }\end{array}$ \\
\hline $\begin{array}{l}\text { Yos.s, Yos.s, and Meorman } \\
\text { (2005) }\end{array}$ & $\begin{array}{l}\text { "... definimos EO como uma dispo sição ao nível da empresa em se envolver em } \\
\text { comportamentos (as sunção de riscos, inovação, proatividade, autonomia e } \\
\text { agres sividade competitiva) que levama alterações na organização ou no mercado } \\
\text { "(p. 1134). }\end{array}$ \\
\hline Avlenitis e Salayeu (2007) & $\begin{array}{l}\text { "EO constitui um fenómene organizacional que reflete um recurso gerencial pelo } \\
\text { qual empresas embarcam em iniciativas proativas e agres sivas para alterar o } \\
\text { cenário competitivo em seu beneficio" (p. 567). }\end{array}$ \\
\hline $\begin{array}{c}\text { Cools e Van den Broesch. } \\
(2007 / 2008)\end{array}$ & $\begin{array}{l}\text { "Orientação empreandedora (OE) refere-se à estratégia de topo da administraçăo } \\
\text { em relação à capacidade de inovação, proatixidade e tomada de riscos" (p. 27). }\end{array}$ \\
\hline Pearce, Fritz, e Davis (2010) & $\begin{array}{l}\text { "A OE é como um conjunto de comportamentos distintos, porém relacionados e } \\
\text { que pos suem as qualidades da capacidade de inovação, proatividade, } \\
\text { agres sividade competitiva, as sumção de riscos e autonomia" (p. 219). }\end{array}$ \\
\hline
\end{tabular}

Fonte: COVIN; WALES, 2012.

Assim, Silveira-Martins e Vaz (20I5, p.2) destacam que orientação empreendedora é entendida como a "capacidade da gestão em conduzir a organização para obter vantagem competitiva, posicionando-se à frente dos seus concorrentes, agregando valor aos produtos/serviços, antecipando-se às demandas de mercado, mesmo que seja necessário assumir riscos”.

\section{Dimensões da orientação empreendedora}

Com base nestes pressupostos das diferentes abordagens sobre as dimensões da 
QUADRO 2 - Dimensões da orientação empreendedora

\begin{tabular}{|c|c|c|c|c|c|c|}
\hline Autores & $\begin{array}{c}\text { Dimensão } \\
\text { Inovatividade }\end{array}$ & $\begin{array}{c}\text { Dimensão } \\
\text { Proatividade }\end{array}$ & $\begin{array}{c}\text { Dimensão } \\
\text { Assunção de } \\
\text { Riscos }\end{array}$ & $\begin{array}{l}\text { Dimensão } \\
\text { Autonomia }\end{array}$ & $\begin{array}{c}\text { Dimensão } \\
\text { Agressividade } \\
\text { Competitiva }\end{array}$ & $\begin{array}{l}\text { Dimensão } \\
\text { Redes de } \\
\text { Relações }\end{array}$ \\
\hline Miller (1983) & $\mathrm{x}$ & $\mathrm{x}$ & $\mathrm{X}$ & & & \\
\hline Covin e Slevin $(1989,1991)$ * & $x$ & $x$ & $x$ & & & \\
\hline Covin e Covin (1990) * & $x$ & $x$ & $x$ & & $x$ & \\
\hline Guth e Ginsberg (1990) & $x$ & $x$ & $x$ & & & \\
\hline Zahra e Covin (1995) & $\mathrm{x}$ & $x$ & $x$ & & & \\
\hline Lumpkin e Dess (1996) & $x$ & $x$ & $x$ & $x$ & $x$ & \\
\hline Morris, Lewis e Sexton (1994) & $x$ & $x$ & $x$ & & & \\
\hline Wiklund (1999) & $x$ & $x$ & $x$ & & & \\
\hline Messeghem (2003) & $x$ & $x$ & $x$ & & & \\
\hline Richard et al. (2004) & $x$ & $x$ & $x$ & & & \\
\hline Mello e Leão (2005) ** & $x$ & $x$ & $x$ & $x$ & $x$ & $x$ \\
\hline Wiklund e Shepherd (2005) & $x$ & $x$ & $x$ & & & \\
\hline Covin, Green e Slevin (2006) & $x$ & $x$ & $x$ & & & \\
\hline Lazzarotti et al. (2015) & $x$ & $X$ & $x$ & $x$ & $x$ & $x$ \\
\hline
\end{tabular}

Fonte: Adaptado de Martens; Freitas e Andres (2011).

* Estes estudos consideram agressividade competitiva na dimensão proatividade, até mesmo como sinônimos. Para eles, uma empresa proativa compete agressivamente com outras organizações. Em Covin e Covin (1990) é empregada como escala de medida da agressividade competitiva a mesma escala utilizada em Covin e Slevin (1989) para medir proatividade.

** Este estudo aponta para uma sexta dimensão denominada Redes de Negócios.

OE, serão abordadas de maneira individual, na sequência, as seis tipologias (inovatividade, proatividade, assunção de riscos, autonomia, agressividade, competitividade, redes de negócios ou de relações) identificadas na literatura.

\section{Dimensão Inovatividade}

A inovação é a disposição de uma empresa em apoiar novas ideias, processos criativos e experimentos que levam a novos produtos, serviços ou processos tecnológicos (LUMPKIN; DESS, 1996). O fundamento desse conceito pode ser encontrado nos estudos de empreendedorismo de Joseph Schumpeter (1942), em que se relata que a entrada de novas combinações inovadoras em um marketplace (local onde se faz comércio de bens e serviços) induz ao progresso da sociedade, uma vez que ideias inovadoras alteram as condições de mercado existentes, estimulando uma nova demanda e criando um processo que Schumpeter chama de "destruição criativa".

Freeman e Perez (1988) tratam sobre a inovação radical e incremental. De acordo com os autores, as inovações incrementais se verificam quando há pequenas mudanças nos produtos ou nos processos que possibilitam um aperfeiçoamento na qualidade ou uma redução de custos e aumento de produtividade. Já as inovações radicais referem-se às consequências dos esforços formais de núcleos de inovação e desenvolvimento (I\&D) de empresas, de instituições públicas ou de universidades.

Existem diversas maneiras de estimar o nível de inovatividade em uma empresa: recursos financeiros designados para inovação, recursos humanos vinculados às atividades de inovação, quantidade de novos serviços ou produtos, entre outras (MILLER; FRIESEN, I982; COVIN; SLEVIN, 1989). 
Para Leite (2006), os recursos fundamentais para gerar ações inovadoras são os processos educativos, os quais podem ser designados com objetivo de maximização de riquezas, como um processo socioeconômico, suficiente para propiciar o desenvolvimento. De qualquer maneira, as organizações que dedicam maiores esforços para a inovação tendem a lucrar mais do que seus concorrentes.

\section{Dimensão Proatividade}

A proatividade é o ato de modelar um determinado ambiente inserindo novos produtos, processos ou tecnologias (MILLER; FRIESEN, 1978). Dessa maneira, essa dimensão sempre implicará em tomada de decisões que antecedem uma mudança.Alguns estudiosos, como Miller (1983) e Covin e Slevin (1989), propõem que, para avaliar a proatividade, seja considerada a propensão de uma empresa em liderar o lançamento de novos produtos e, ou, tecnologias, além de estar informada das tendências do mercado atual.

Em complemento, Buss (1987) destaca que a proatividade é o ato de adaptar o ambiente devido ao fato de o empreendedor não ser um observador passivo das pressões ambientais, mas um participante ativo na formação de seu próprio ambiente.

Assim, a proatividade é entendida como a busca por diferentes oportunidades, que pode estar relacionada ou não à atual linha de operações da empresa, à inserção de novos produtos e marcas antes da concorrência e à exclusão estratégica de operações que estão em um estágio maduro ou de operações que estão em um estágio de declínio em seu ciclo de vida (VENKATRAMAN, 1989).

Para Lumpkin e Dess (1996), a proatividade diz respeito às iniciativas de antecipação e busca por novas oportunidades, além da participação em mercados emergentes. Os autores também relatam que uma empresa pode criar uma vantagem competitiva antecipando-se às mudanças da demanda futura. Ainda, Hughes e Morgan (2007) relatam que a proatividade demonstra uma perspectiva do tipo estratégico prospectiva, proposta por Miles e Snow (1978), que leva as organizações a buscarem e a anteciparem oportunidades, para obter vantagens pioneiras e moldar a direção do ambiente.

Nessa conjuntura, as organizações proativas acompanham tendências, descobrem futuras necessidades de clientes e antecipam as mudanças de demandas ou problemas que estão surgindo, com intuito de alcançar novas oportunidades (DESS; LUMPKIN, 2005). Sendo assim, a dimensão proatividade tem extrema importância no que tange às iniciativas tomadas no decorrer do processo empreendedor (KRAUS et al., 20I2).

\section{Dimensão Assunção de Riscos}

Conforme Venkatraman (1989), essa dimensão busca o nível de risco refletido em várias decisões de alocação de recursos, bem como na seleção de produtos e mercados, criando, de alguma maneira, métodos e padrões de tomadas de decisões a nível organizacional.

A assunção de risco retrata uma conduta de assumir grandes obrigações financeiras, buscando obter altos lucros por capturar oportunidades no mercado (LUMPKIN; DESS, 1996). Os autores também abordam que, para detectar o comportamento de risco de uma empresa, a literatura escrita por Miller (1983) é bem aceita, pois foca na inclinação da organização em engajar-se em projetos ou ideias de riscos e na preferência dos gestores por atuar com certa ousadia para atingir os objetivos pretendidos. 
Nesse contexto, verifica-se que a assunção de riscos reflete a capacidade da organização em aproveitar determinada oportunidade, mesmo que não seja certeza de sucesso e também de agir sem saber como será o resultado final. São identificados três tipos de riscos que uma empresa e seus empresários geralmente enfrentam: (I) riscos de negócios, que envolve arriscar no desconhecido com retorno incerto, como, por exemplo, entrar em mercados não testados; (2) riscos financeiros, em que uma organização toma emprestado grande volume de recursos visando ao crescimento, refletindo a dicotomia risco e retorno; (3) risco pessoal, que se refere aos riscos que um gestor assume ao adotar um padrão ou método em favor de uma ação estratégica (LUMPKIN; DESS, 2005). Em complemento, Morris et al. (2008) destacam que o comportamento empresarial envolve investir uma parte significativa dos recursos em um projeto propenso a falhas.

Em um estudo aplicado no ambiente de jogos esportivos Jordan et al., (2009) sugerem que o emprego de estratégias propensas a riscos pode produzir benefícios sobre estratégias avessas aos riscos e que a utilização e o conhecimento de comportamentos de riscos podem ser componentes importantes para o êxito da gestão de atividades.

\section{Dimensão Autonomia}

A dimensão autonomia diz respeito à liberdade para agir de forma independente, estimulando o indivíduo a criar novas ideias ou visões, e, com isso, contribuindo para o processo empreendedor. No ambiente organizacional, a autonomia refere-se à ação sem pressão organizacional. Sendo assim, embora alguns elementos como disponibilidade de recursos ou considerações organizacionais internas possam alterar as rotas de iniciativas de novos empreendimentos, eles não são suficientes para eliminar os processos empreendedores autônomos, que comandam novos negócios. No transcorrer do processo, os indivíduos envolvidos são desimpedidos para agir independentemente e para tomar decisões fundamentais (LUMPKIN; DESS, 1996).

Conforme Miller (1983), as organizações com maiores níveis de empreendedorismo possuem líderes mais autônomos. Em uma pesquisa aplicada pelo autor, foi possível identificar que em pequenas empresas, que possuem uma autoridade centralizada, ou seja, gestores que conduzem o conhecimento da organização, estas apresentam um alto índice de atividade empreendedora.

Por outro prisma, para que ocorra uma autonomia forte dentro das organizações, é preciso possuir uma cultura interna que promova a ação independente e a procura de oportunidades sem constrangimento social (LEE; PETERSON, 2000).

Bouchard (2002) relata que a autonomia concedida aos colaboradores visa à expansão dos negócios, para fora da empresa, à busca de oportunidades. Dess e Lumpkin (2005) afirmam que o raciocínio empreendedor deve ser incentivado nos colaboradores da organização. Normalmente, organizações que possuem uma visão global empreendedora empregam uma metodologia top-down para encorajar o desenvolvimento de atividades empreendedoras.

A autonomia permite que os membros de uma organização tenham liberdade e flexibilidade na determinação de suas ações (LUMPKIN; COGLISER; SCHNEIDER, 2009). Organizações que atuam com uma cultura baseada na autonomia permitem aos colaboradores a oportunidade de 
executarem suas tarefas de forma eficaz, devido à estimulação da criatividade, independência e auto-organização.

\section{Dimensão Agressividade Competitiva}

Alguns pesquisadores, como Covin e Slevin (1989) e Covin e Covin (1990), relacionam essa dimensão (agressividade competitiva) com a proatividade, ou igualam os conceitos das duas dimensões. No entanto, embora exista uma forte relação entre essas duas dimensões, Lumpkin e Dess (200 I) afirmam que a proatividade é uma resposta a oportunidades, e a agressividade competitiva é uma resposta a ameaças, sendo que as duas podem ocorrer, sequencial e dinamicamente, em uma organização.

Conforme Venkatraman (1989), as organizações com agressividade competitiva buscam ganhar posições de forma mais rápida do que os concorrentes. A agressividade competitiva pode ser baseada em inovação de produto, desenvolvimento de mercado, altos investimentos para evoluir na participação de mercado, entre outros. Ainda de acordo com o mesmo autor, a agressividade competitiva também transmite a ideia de explosão, ou seja, o crescimento da posição competitiva em um curto espaço de tempo,a estratégia de multiplicação e a busca de parte do mercado, como uma relevante direção para alcançar a rentabilidade.

A agressividade competitiva caracterizase por realizar ações para reduzir ou eliminar as ações da concorrência, muitas vezes utilizando-se de métodos não tradicionais para obter os resultados esperados. Os métodos utilizados vão desde ações que diminuem a rentabilidade para ganhar uma fatia no mercado, operando com preços abaixo do que a concorrência, até agir de acordo com as ações dos concorrentes, respon- dendo agressivamente (VENKATRAMAN, 1989; CHEN; HAMBRICK, 1995).

Corroborando Venkatraman (1989) e Chen e Hambrick (1995), Lumpkin e Dess (1996) afirmam que a agressividade competitiva reflete aos esforços intensos para ser o número um no mercado e caracteriza-se por uma postura permanente combativa ou uma resposta agressiva para transcender ameaças da concorrência, fazendo uso muitas vezes de métodos não tradicionais de competição e disputa.

\section{Dimensão Redes de Negócios ou de Relações}

Mais recentemente, uma sexta dimensão foi apontada nos estudos de Mello e Leão (2005). Trata-se de uma dimensão relevante no campo do empreendedorismo, visto que cada vez mais os relacionamentos são de extrema importância para o ingresso em novos mercados, para internacionalização dos negócios e, inclusive, para a sustentação das organizações (PAIVA et al., 20l0; BASILE, 20I2; COVIN; MILLER, 20I4).

McClelland (1972) já alertava que a adoção de estratégias deliberadas para influenciar os outros e, ou, trabalhar com pessoaschave, como agentes para atingir objetivos, são comportamentos realizados por empreendedores. Filion (1991) corrobora esse pensamento e entende que o desenvolvimento de uma visão empresarial está embasado nos relacionamentos do empreendedor.

Ao discutir a modalidade inovadora das organizações japonesas no pós-fordismo, Coriat (1994) relata que a habilidade relacional acrescentava inovações nos relacionamentos entre firmas, por intermédio de produtos e conhecimentos disponíveis e necessários à geração dos seus resultados.

Zoschke e Lima (2006), em um estudo de 
marketing empreendedor, realizado em empresas de pequeno porte de base tecnológica, identificaram que as redes de relações são fundamentais no processo de formação de visão e competências dos empreendedores. Jenssen e Nybakk (2009) apontam que a participação das organizações em cursos e, ou, conferências proporciona aos colaboradores oportunidades de gerar novas ideias, além de mais conhecimento.

Ao revisitar sua obra seminal (MILLER, 1983), Miller (20I I) destacou a possibilidade de existirem relações entre orientação empreendedora e outras teorias, entre elas, a de redes. $\mathrm{O}$ autor aborda algumas questões, como o equilíbrio entre as relações com clientes, concorrentes e fornecedores, e sua influência sobre a $\mathrm{OE}$, salientando a necessidade de mais estudos que contemplem as ligações entre a $\mathrm{OE}$ e as estruturas de rede.

Com base na literatura sobre orientação empreendedora, as dimensões podem ser caracterizadas pelos elementos teóricos, como é apresentado no Quadro 3.

\section{QUADRO 3 - Elementos das dimensões da orientação empreendedora}

\begin{tabular}{|c|c|c|}
\hline $\begin{array}{l}\text { Dimensōes } \\
\text { da OE }\end{array}$ & Elementos que caracterizam as dimensōes da $\mathrm{OE}$ & Autores \\
\hline \multirow{2}{*}{ 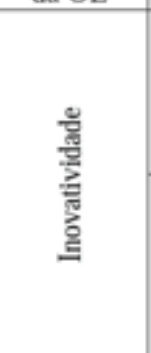 } & $\begin{array}{l}\text { Novas linhas de produtos/serviços; Forte enfâse em P\&D, liderança tecnológica e inovação; } \\
\text { Modificaçōes em produtos ou serviços e em linhas de produtos/serviços; Investimento em } \\
\text { inovaçōes; Recursos humanos vinculados a tarefas de inovação; Regularidade em mudanças } \\
\text { nos produtos ou serviços e em linhas de produtos ou serviços; Número de novos produtos } \\
\text { ou serviços. }\end{array}$ & $\begin{array}{l}\text { Miller e Friesen (1982) } \\
\text { Covin e Slevin (1989) }\end{array}$ \\
\hline & $\begin{array}{l}\text { Inovação administrativa, tecnológica, em produto e mercado; Criatividade e } \\
\text { experimentação; Apoiar e engajar-se em novidades, ideias, praticas e processos criativos; } \\
\text { Iniciativas inovativas de difícil imitação por parte dos competidores; Assegura } \\
\text { investimentos em pesquisas e desenvolvimento (P\&D) mesmo em periodos de dificuldade } \\
\text { económica; Investe em novas tecnologias, P\&D e melhoria contínua. }\end{array}$ & $\begin{array}{l}\text { Lumpkin e Dess (1996) } \\
\text { Dess e Lumpkin (2005) }\end{array}$ \\
\hline \multirow{3}{*}{ 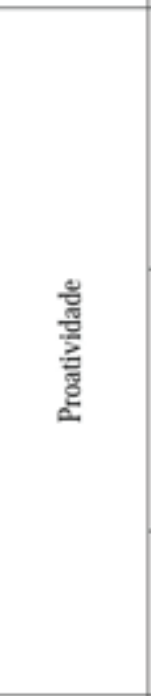 } & $\begin{array}{l}\text { Ajustar o ambiente pela introdução de novos produtos e tecnologias; Produtos e serviços } \\
\text { mais inovativos; Mudanças continuas em produtos e serviços; Empresa criativa e inovativa; } \\
\text { Monitoramento contínuo do mercado; Entrada em novos mercados; Flexibilidade } \\
\text { tecnológica (assegura-se da disponibilidade e acessibilidade de pessoas, recursos e } \\
\text { equipamentos necessários para desenvolver novos produtos e serviços); Multiplas } \\
\text { tecnologias; Habilidade das pessoas (em termos tecnológicos); Foco em marketing e P\&D; } \\
\text { Planejamento orientado a problemas e busca de oportunidades; Estrutura orientada para } \\
\text { produtos/serviços; Procedimentos de controle descentralizados e participativos. }\end{array}$ & $\begin{array}{l}\text { Miller e Friesen (1978) } \\
\text { Miles e Snow (1978) }\end{array}$ \\
\hline & $\begin{array}{l}\text { Ser pioneiro no desenvolvimento, aperfeiçoamento e introdução de novos produtos, } \\
\text { tecnologias e serviços; Normalmente é o primeiro a inserir novos produtos ou serviços, } \\
\text { técnicas administrativas e tecnologias operacionais; Frequentemente inicia as açōes as quais } \\
\text { os competidores respondem; Constantemente busca novas oportunidades relacionadas às } \\
\text { atuais operações; Geralmente é a primeira a introduzir novos produtos e marcas no } \\
\text { mercado; Constantemente procura por novos negócios que podem ser adquiridos; } \\
\text { Geralmente, antecipa-se à concorrência expandindo capacidades; Elimina operações em } \\
\text { avançados estágios do ciclo de vida. }\end{array}$ & $\begin{array}{l}\text { Miller (1983) } \\
\text { Covin e Slevin (1989) } \\
\text { Venkatraman (1989) }\end{array}$ \\
\hline & $\begin{array}{l}\text { Tendências a iniciar ataques competitivos; Monitoramento contínuo do mercado; Identificar } \\
\text { futuras necessidades dos clientes; Antecipar as mudanças. Antecipar problemas; Forte } \\
\text { tendência a estar à frente dos concorrentes na introdução de ideias ou produtos. }\end{array}$ & $\begin{array}{l}\text { Chen e Hambrick } \\
\text { (1995) } \\
\text { Lumpkin e Dess (1996, } \\
\text { 2001) } \\
\text { Dess e Lumpkin (2005) }\end{array}$ \\
\hline \multirow{5}{*}{ 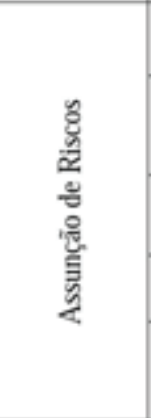 } & $\begin{array}{c}\text { Propensão em apoiar projetos de risco; Preferência dos gerentes por agir com ousadia para } \\
\text { atingir os objetivos da organização. }\end{array}$ & Miller (1983) \\
\hline & $\begin{array}{l}\text { Forte inclinação para projetos de alto risco (com chances de alto retorno); Necessidade de } \\
\text { açōes de grande porte para alcançar os objetivos da organização. }\end{array}$ & $\begin{array}{l}\text { Miller e Friesen } \\
\qquad(1982) ; \\
\text { Covin e Slevin (1989) }\end{array}$ \\
\hline & $\begin{array}{l}\text { Visão pouco conservadora quando tomam decisões maiores; Operações geralmente } \\
\text { caracterizadas como de alto risco. }\end{array}$ & Venkatraman (1989) \\
\hline & $\begin{array}{c}\text { Tipicamente adota postura agressiva visando maximizar a probabilidade de explorar } \\
\text { oportunidades potenciais; }\end{array}$ & Covin e Slevin (1989) \\
\hline & $\begin{array}{l}\text { Comportamento de assumir risco formal em negócios; Encorajar a assumir risco financeiro; } \\
\text { Encorajar a assumir risco pessoal; Caracterizadas com um comportamento de assumir } \\
\text { riscos. }\end{array}$ & $\begin{array}{l}\text { Lumpkin e Dess (1996) } \\
\text { Dess e Lumpkin (2005) }\end{array}$ \\
\hline
\end{tabular}




\begin{tabular}{|c|c|c|}
\hline \multirow{3}{*}{ 䜌 } & Lideres com comportamento autônomo. & Miller (1983) \\
\hline & $\begin{array}{c}\text { Cultura que promova à ação independente, para manter controle pessoal, e para buscar } \\
\text { oportunidades sem constrangimento. }\end{array}$ & Lee e Peterson (2000) \\
\hline & $\begin{array}{c}\text { Pensamento empreendedor deve ser encorajado nas pessoas; Pensamento e ação } \\
\text { independente; Pensamento criativo e estúmulo a novas ideias; Encorajar iniciativas } \\
\text { empreendedoras; Equipes de trabalho autônomas; Coordenar atividades autônomas; Medir e } \\
\text { monitorar atividades autônomas. }\end{array}$ & Dess e Lumpkin (2005) \\
\hline \multirow{4}{*}{ 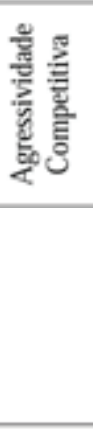 } & $\begin{array}{c}\text { Gastos agressivos (se comparados com os concorrentes) em marketing, qualidade de } \\
\text { produtos e serviços, ou capacidade de manufatura. }\end{array}$ & $\begin{array}{c}\text { Macmillan e Day } \\
\text { (1987, apud } \\
\text { Lumpkin e Dess, 2001) }\end{array}$ \\
\hline & $\begin{array}{l}\text { Cortar a lucratividade para ganhar parcela de mercado; Cortar preços para aumentar } \\
\text { participação no mercado; Colocar preços abaixo da competição: Buscar posiçōes de } \\
\text { participação no mercado à custa de fluxo de caixa ou rentabilidade. }\end{array}$ & Venkatraman (1989) \\
\hline & $\begin{array}{l}\text { Mover-se em função das açōes dos concorrentes; Responder agressivamente às açōes dos } \\
\text { concorrentes. }\end{array}$ & $\begin{array}{l}\text { Chen e Hambrick } \\
\text { (1995) }\end{array}$ \\
\hline & $\begin{array}{l}\text { Adota postura competitiva do tipo "desfazer o competidor"; Reproduz práticas ou técnicas } \\
\text { de negócios dos competidores de sucesso; Postura agressiva para combater tendências da } \\
\text { indústria que podem ameaçar a sobrevivência ou posição competitiva; Utilização de } \\
\text { métodos de competição não convencionais; É agressiva e intensamente competitiva. }\end{array}$ & $\begin{array}{l}\text { Lumpkin e Dess (1996, } \\
\text { 2001): } \\
\text { Dess e Lumpkin (2005) }\end{array}$ \\
\hline \multirow{6}{*}{ 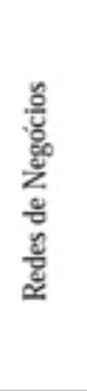 } & Desenvolvimento de uma visão empresarial através dos relacionamentos do empreendedor. & Filion (1991) \\
\hline & Molda visão e competências dos empreendedores. & Zoschke e Lima (2006) \\
\hline & $\begin{array}{l}\begin{array}{l}\text { Participação de empreendedores em reuniōes e eventos sociais para terem acesso a } \\
\text { financiamentos. }\end{array} \\
\end{array}$ & Sheng (2008) \\
\hline & Participação da empresa em cursos e conferências. & $\begin{array}{l}\text { Jenssen e Nybakk } \\
\text { (2009) }\end{array}$ \\
\hline & $\begin{array}{l}\text { Celebração de acordos de cooperação, trabalho colaborativo na forma de parcerias, } \\
\text { estabelecimento de alianças estratégicas e a atuação em rede sâo alguns dos mecanismos } \\
\text { utilizados pelas empresas para o desenvolvimento de inovações. }\end{array}$ & $\begin{array}{l}\text { Oberg e Grundström } \\
\text { (2009) }\end{array}$ \\
\hline & Equilibrio entre as relaçōes com clientes, concorrentes e fornecedores. & Miller (2011) \\
\hline
\end{tabular}

Fonte: Elaborado pelos autores a partir dos estudos de Miller e Friesen (1978; 1982), Miles e Snow (1978), Miller (1983), MacMillan e Day (1987, apud LUMPKIN; DESS, 2001), Covin e Slevin (1989), Venkatraman (1989), Filion (1991), Chen e Hambrick (1995), Lumpkin e Dess (1996; 2001), Lee e Peterson (2000), Dess e Lumpkin (2005), Zoschke e Lima (2006), Sheng (2008), Jenssen e Nybakk (2009), Oberg e Grundström (2009), Miller (2011).

\section{METODOLOGIA}

A presente pesquisa é do tipo quantitativo, onde a técnica utilizada foi a bibliometria. Para tanto, a pesquisa amparou-se nos seguintes descritores: orientação empreendedora, entrepreneurial orientation, orientación emprendedora, por entender que os mesmos representam a temática orientação empreendedora nos idiomas: português, inglês e espanhol. Esses termos foram filtrados pelo título e, ou, resumo dos artigos.

Como fonte para coleta de dados, utilizaram-se as bases Ebscohot, Periódicos Capes, ProQuest e Spell. Por se tratarem de bases de dados consolidadas e com acesso a milhares títulos de periódicos, além do acesso disponibilizado pelo programa de pós-graduação, a busca resultou em um total de 350 artigos, compreendendo um espaço temporal de 12 anos (2003 2015). Acredita-se que esse recorte de tempo ocorra em função das restrições contratuais existentes nos acessos.

$\mathrm{Na}$ sequência, foi aplicado o filtro de eliminação dos artigos duplicados, após a exclusão daqueles que não se enquadravam no Qualis/Capes entre AI $\longmapsto$ B2 ou no fator de impacto. $O$ último filtro aplicado foi o de analisar individualmente cada um dos artigos restantes na base de dados, para verificar se a temática orientação empreendedora correspondia ao construto abordado no referencial teórico, evitando assim textos versando genericamente sobre ou sem nexo com o objetivo da pesquisa.Após a aplicação desses filtros meto- 
dológicos, restaram II 2 artigos que foram analisados valendo-se de softwares como o pacote estatístico Excel $\AA$ 2007, Ucinet $\AA$ versão 6.3।4 e NetDraw $®$ versão 2.098 .

\section{ANÁLISE DOS DADOS}

Nesta seção, serão apresentados os resultados da pesquisa bibliométrica realizada, refletindo o estado da arte do construto orientação empreendedora (OE) no espaço temporal dos últimos 12 anos. Assim, a primeira análise realizada procurou identificar quais as temáticas os cientistas têm associado com a $\mathrm{OE}$ em suas pesquisas. A preocupação da academia tem sido direcionada a diferentes abordagens. No entanto, algumas recebem maior atenção, tais como: desempenho organizacional; dinamismo ambiental; chief executive officer
(CEO); novos empreendimentos; capacidade de absorção; capacidade de inovação; confiança; intensidade competitiva; recursos intangíveis; capital social; redes de relacionamentos, entre outros.

As temáticas identificadas como associadas a OE, nas pesquisas, podem ser observadas na Figura I. Observa-se que as palavras em destaque (tamanho) representam aquelas que receberam maior atenção dos cientistas. Por outra ótica, as demais também foram abordadas em pesquisas, ainda que em menor quantidade de vezes.

Verificou-se que, do total de artigos, 20 (I7\%) foram publicados em periódicos classificados no estrato AI do Qualis/Capes e 16 (I4\%) no A2. Nos demais estratos (BI e B2), foi publicado o total de 12 artigos. Com relação aos periódicos detentores de

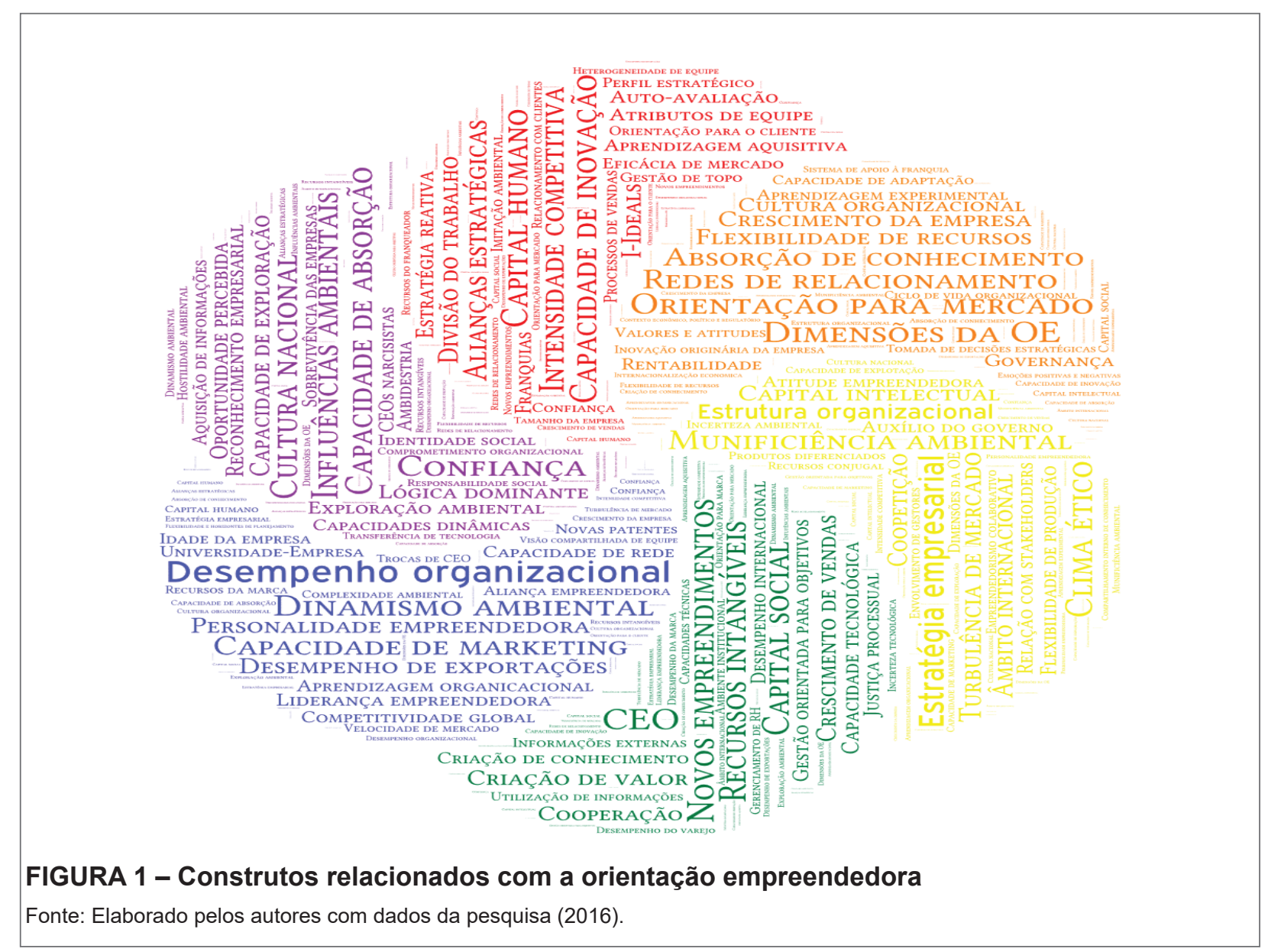


fator de impacto, observou-se que aqueles com fator $\leq 3,06$ publicaram o quantitativo de 38 (33,92\%) artigos; os demais fatores $(>3,06)$ publicaram a mesma quantidade. Também se percebeu que $69,64 \%$ dos artigos da amostra foram publicados nos anos de $201 \mathrm{I}$ a 2015 , com picos no volume de publicação em 2013, com 23 artigos, e, em 2014 , com 20 artigos. Os resultados demonstram que houve um crescimento na quantidade de estudos publicados sobre $o$ tema nos últimos cinco anos, conforme pode-se observar nos Gráficos I e 2.

Observa-se que, dentre os países de origem dos pesquisadores interessados na temática, os Estados Unidos da América representam $40 \%$ da amostra, sendo seguido por Reino Unido (28\%) e Brasil (I $2 \%)$, Holanda (6\%) e Espanha (3\%). Outros países, como Alemanha, Chile, Noruega, China e Colômbia representaram I\% cada. Do to- tal da amostra, em $6 \%$ não foi possível identificar a origem dos pesquisadores. Conforme McDougall e Oviatt (2000), a maioria dos estudos relacionados com a temática do empreendedorismo são provenientes dos Estados Unidos ou de países anglosaxônicos. Os Estados Unidos concentram a grande maioria dos pesquisadores ligados ao tema. Porém, o reconhecimento da importância do empreendedorismo internacional tem atraído cada vez mais a atenção de pesquisadores do mundo todo, internacionalizando os membros dessa comunidade e suas atividades.

Ao analisar os periódicos que mais publicaram artigos sobre a temática, constatou-se que as seguintes revistas foram as mais expressivas nessa categoria: Entrepreneurship Theory and Practice publicou 18 $(16,07 \%)$ artigos; Journal of Business Venturing, 10 (8,92\%) artigos; International Jour-

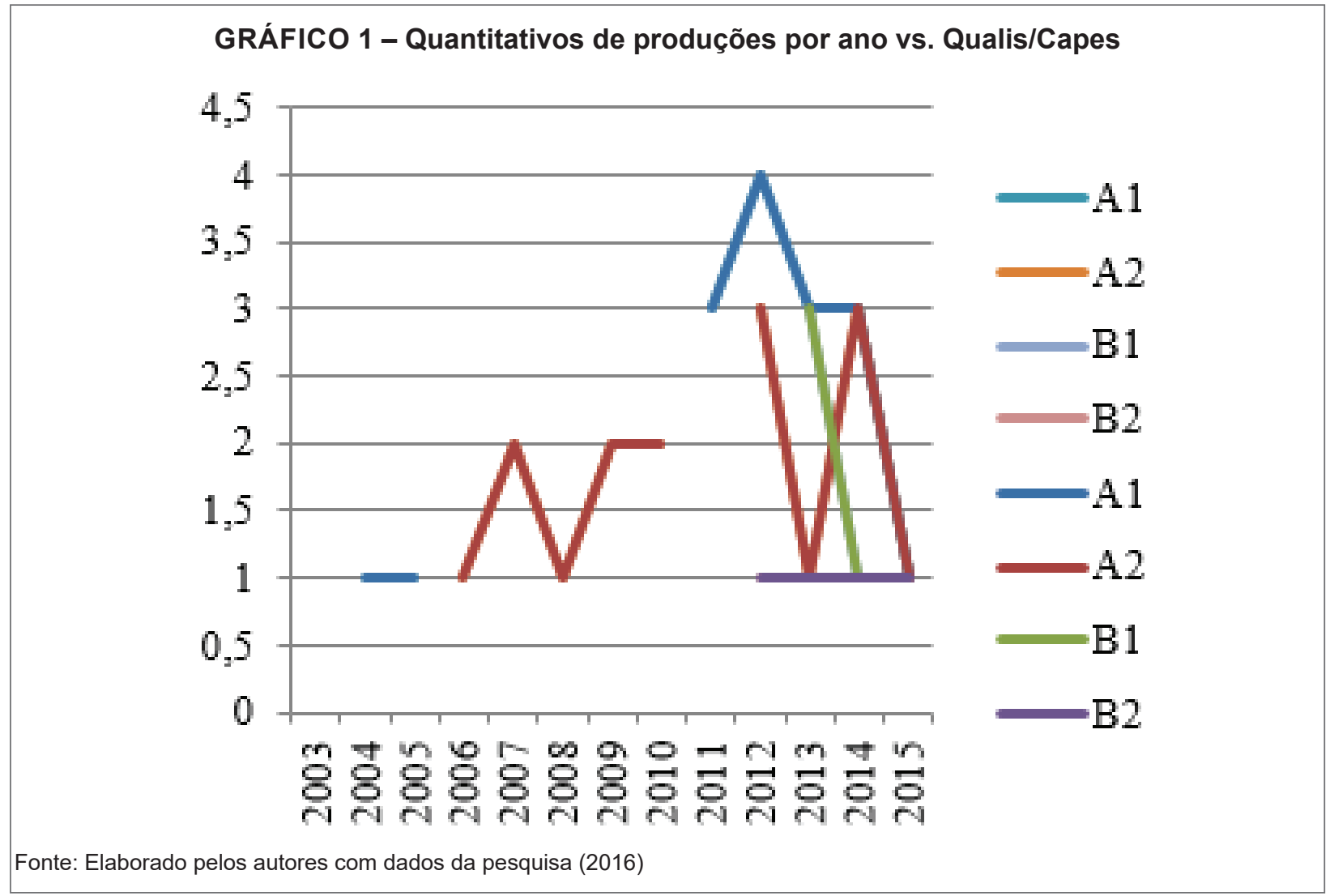




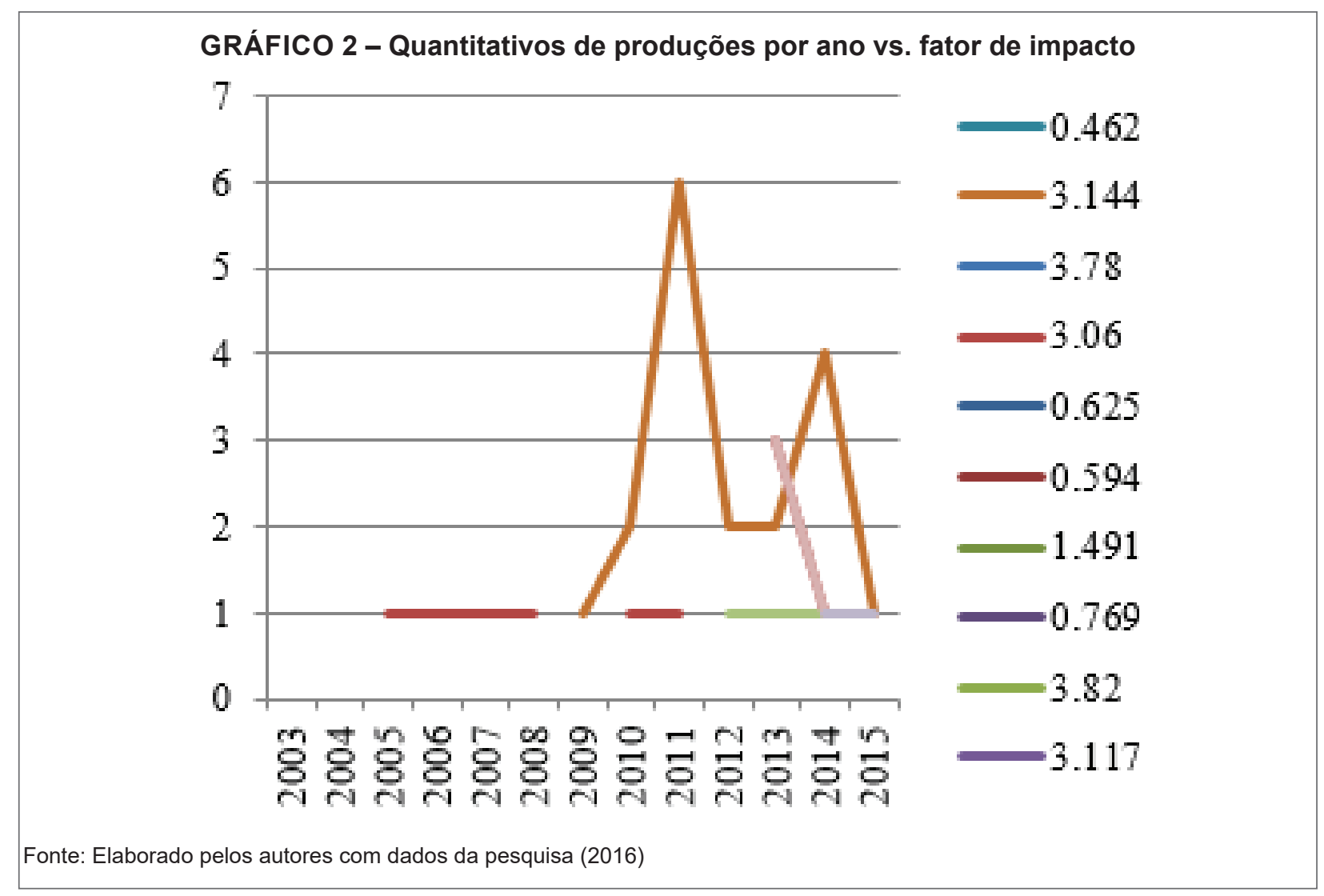

nal of Entrepreneurship and Small Business, 5 (4,46\%) artigos; Industrial Marketing Management, 5 (4,46\%) artigos; Strategic Management Journal, 4 (4,46\%) artigos.

Verificou-se, ainda, que o International Small Business Journal, Journal of Business Research, Management Decision e o European Management Journal publicaram três artigos cada um. Com dois artigos publicados, estão os periódicos: Journal of Operations Management; Research Policy; Tourism Management; Journal of Management Studies; Journal of Retailing and Consumer Services; REAd - Revista Eletrônica de Administração (POA); Turismo Visão e Ação; International Journal OfTechnology Management; Journal of Organizational Change Management; Journal of Business Ethics; Journal of International Entrepreneurship; Cuadernos de Economia y Dirección de La Empresa; e European Journal of Marketing.
Os demais periódicos publicaram um (I) artigo no período analisado. Tendo em vista que foram 112 artigos analisados, distribuídos em 54 periódicos, esse cenário representa uma média de 2,07 artigos publicados por periódico. Sendo assim, o mapeamento dos principais periódicos interessados na temática torna-se importante para direcionar futuras submissões, além de otimizar as pesquisas sobre o tema.

Ao analisar os objetos de pesquisa relacionados à $\mathrm{OE}$, verificou-se que $17 \%$ dos artigos foram desenvolvidos com o foco em organizações de diversos setores, não delimitando um determinado segmento. Os resultados também demonstram que 15\% dos artigos tiveram seus estudos direcionados para o setor tecnológico, seguido por pesquisas aplicadas em micro e pequenas empresas que representam 13\% do total. 
Estudos teóricos direcionados para a discussão das dimensões da orientação empreendedora resultaram em I $3 \%$ da amostra. O segmento industrial e incubadoras tiveram $8 \%$ e $4 \%$ da participação total dos estudos, respectivamente. Os setores de hotelaria, empresas de manufatura, joint ventures, empresas familiares e entidades sem fim lucrativo obtiveram 3\% dos resultados da amostra. Atividades exportadoras, franquias e centros de empreendedorismo tiveram $2 \%$ de participação nos estudos analisados. E com $1 \%$ do total da amostra, os setores estudados foram: grupos de teatro, subsidiárias, sociedades anônimas de grande porte, esportes, financeiro, biotecnologia, turismo, varejo, estudantes universitários, universidades e agroindústrias.

Essas informações podem ser importantes para o direcionamento de pesquisas futuras e lacunas de objetos de análise, além de poderem orientar os gestores na construção de estratégias com pesquisas já desenvolvidas. A seguir, observam-se, no Gráfico 3, os setores estudados.

Quando analisadas as redes de pesqui-

\section{GRÁFICO 3 - Objetos de pesquisa}

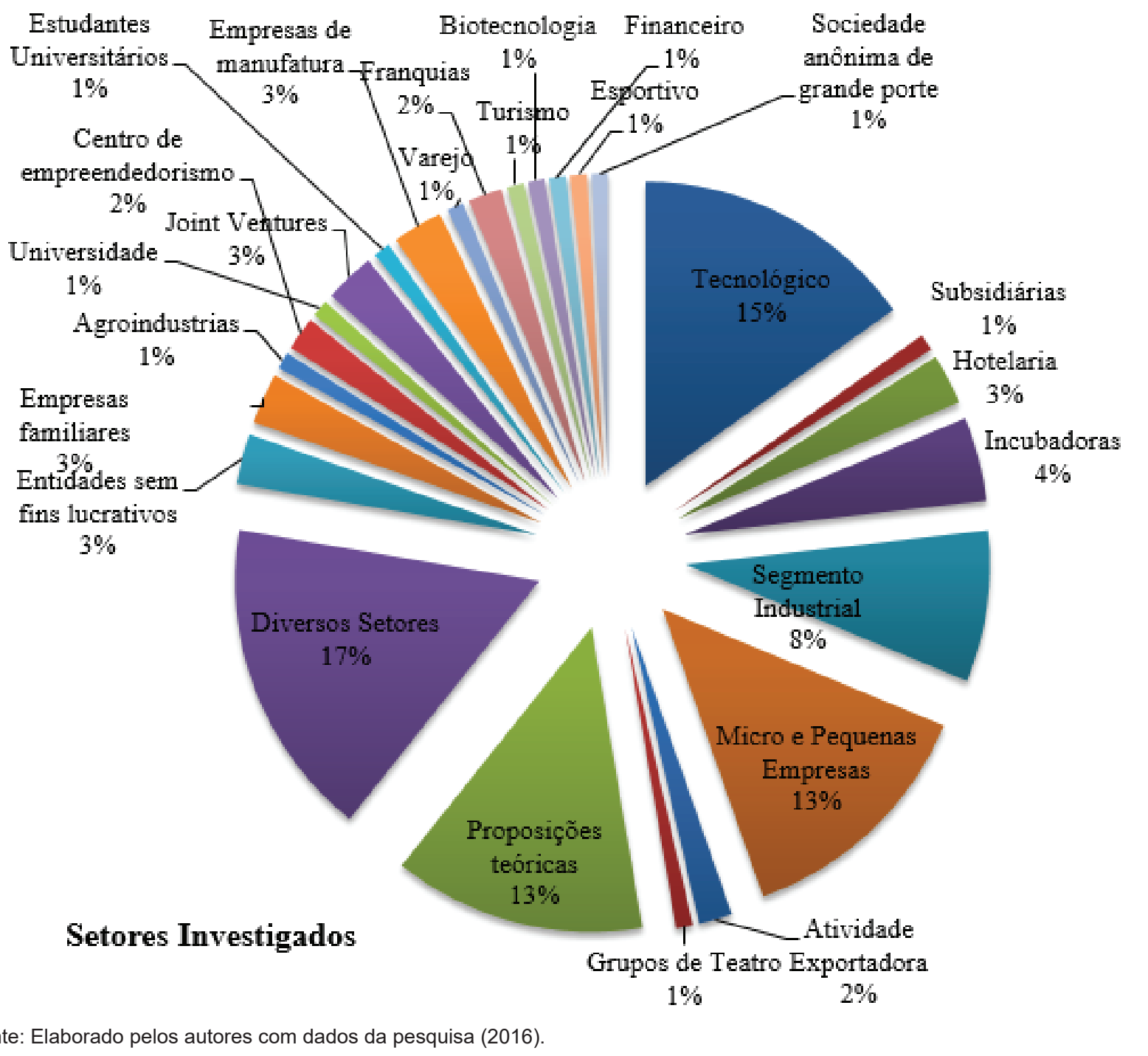


sadores, verificou-se a existência de muitas redes de cientistas interessados na temática. Observa-se que algumas redes podem ser consideradas parcerias para o desenvolvimento da pesquisa, como, por exemplo, Gudmundsson (2014) e Lechner (2014). Por outra óptica, existem também redes com maior complexidade de relações. Por exemplo: Liu (2008, 20 I I), Li (2008, 20 I I), Duan (2008), Liu (20I I), Chen (2009), Lee (2009), Zhao (2009) e Li (2009). Tais dados revelam que esses autores formam redes de cooperação, nessa temática e nessa amostra de artigos. A rede de pesquisadores pode ser observada na Figura 2.

Por outro prisma, a rede de autores que obteve destaque em termos de relações, quando analisada sobre a ótica da centralidade, ou seja, relação ativa com os demais cientistas, é formada porWales (20II, 20 I2, 20I3). De acordo com o coeficiente estatístico degree, gerado pelo software Ucinet, este pesquisador possui 9 relações do total de 249 relações existentes. A rede deste pesquisador é apresentada na Figura 3.

Vale ainda destacar que alguns pesquisadores desenvolvem suas pesquisas de maneira individual, tais como: Ibeh (2004), Tijssen (2006), Schiavone (2007), García (20I0), Home (20II), Zainol (20I2), Kirkman (20I3), Perlines (20I4), Balodi (20I4), Chien (20I4), Tuan (20I4).

Com relação às conexões entre universidades e seus núcleos de pesquisa, verificou-se que algumas optaram por não estabelecer vínculos com coirmãs. Por exemplo, pode-se destacar: LHU e NTUB; Lynchburg e SUNY; Duce University e Poole College of University; Lund University e University of Bradford, entre outras.

Quanto às universidades, verificou-se que as seguintes universidades não reali- zaram parcerias/redes para o desenvolvimento de suas pesquisas sobre a temática OE: UFPE; SSAV; UniSZA; IIM Lucknow; Universidad de Sevilla; University of Tehran; CWTS-Leiden; Universitat Jaume I; Les Roches; Aalto University; Universidad de Granada; RWTH Aachen University; Nordlandsforskning; Deakin University; Warwick University; University of Houston; NKFUST; Toulouse Business School; UEH; e Wits University. Por outra óptica, também foi possível identificar a formação de algumas redes de pesquisa em que diversas articulações foram caracterizadas, permitindo a visualização dos elos que as instituições possuem com as demais, tal como observado na Figura 4.

Destacam-se ainda as universidades Ball State University e Lulea University of Technology, quando analisada a estatística de centralidade. Estas universidades possuem, igualmente, 8 laços de entrada e 8 laços de saída, de um total de 168, representando as instituições de ensino com maior atividade em termos de parcerias de pesquisa. É importante ressaltar as redes formadas por essas instituições, pois aprofundam o conhecimento sobre essa temática, além de incentivar novas atividades de ensino, pesquisa e extensão entre as universidades.

Procurou-se identificar quais métodos de pesquisa foram utilizados pelos pesquisadores nos artigos que compõem a amostra. O resultado apontou que $79,46 \%$ dos artigos estão estruturados a partir da pesquisa quantitativa, enquanto $19,64 \%$ utilizaram-se da pesquisa qualitativa. Apenas I\% valeu-se da pesquisa quali-quanti.

Outro aspecto explorado na presente pesquisa reside na identificação dos autores e seus trabalhos, que recebeu maior destaque em termos de citações. Para tanto, 


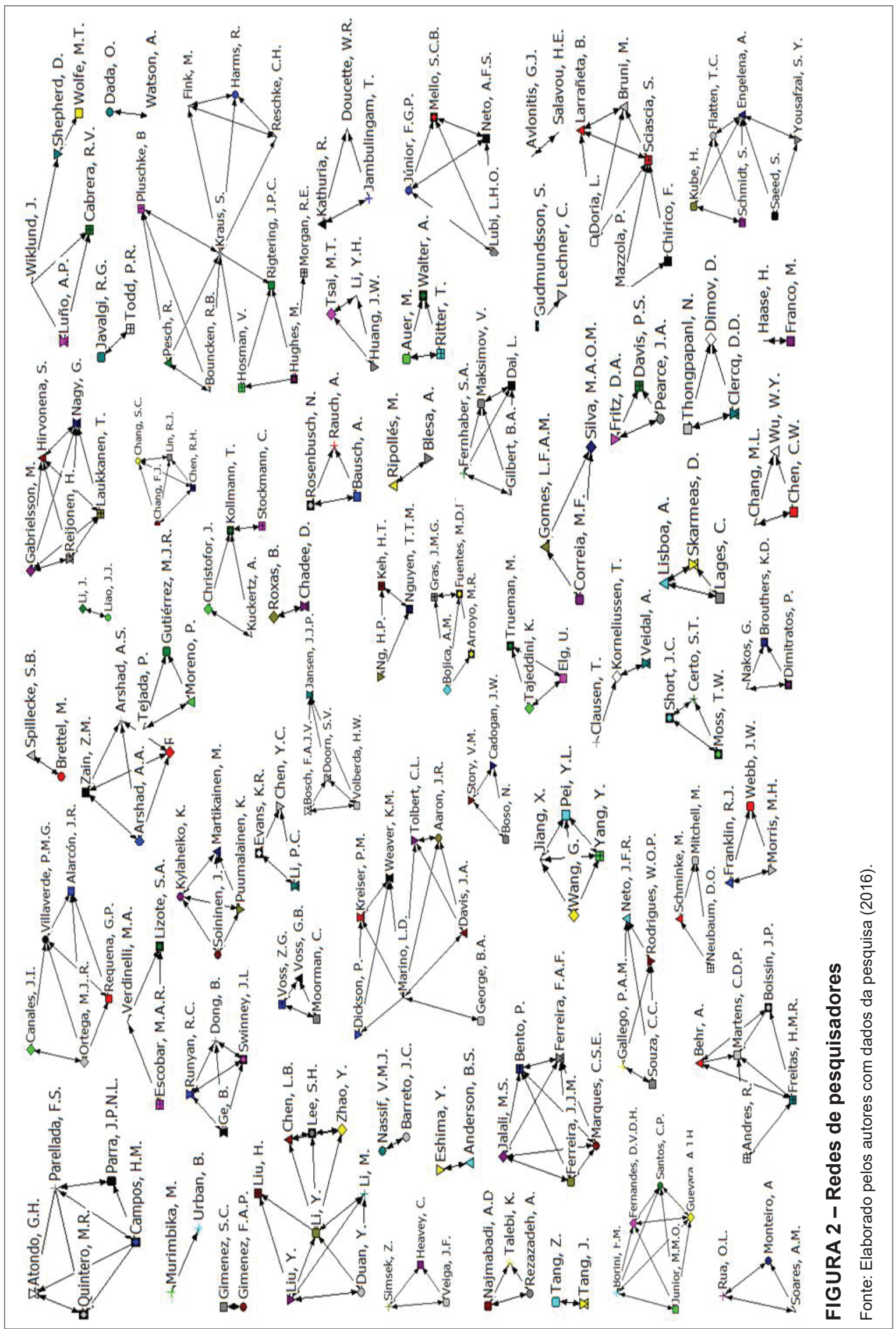




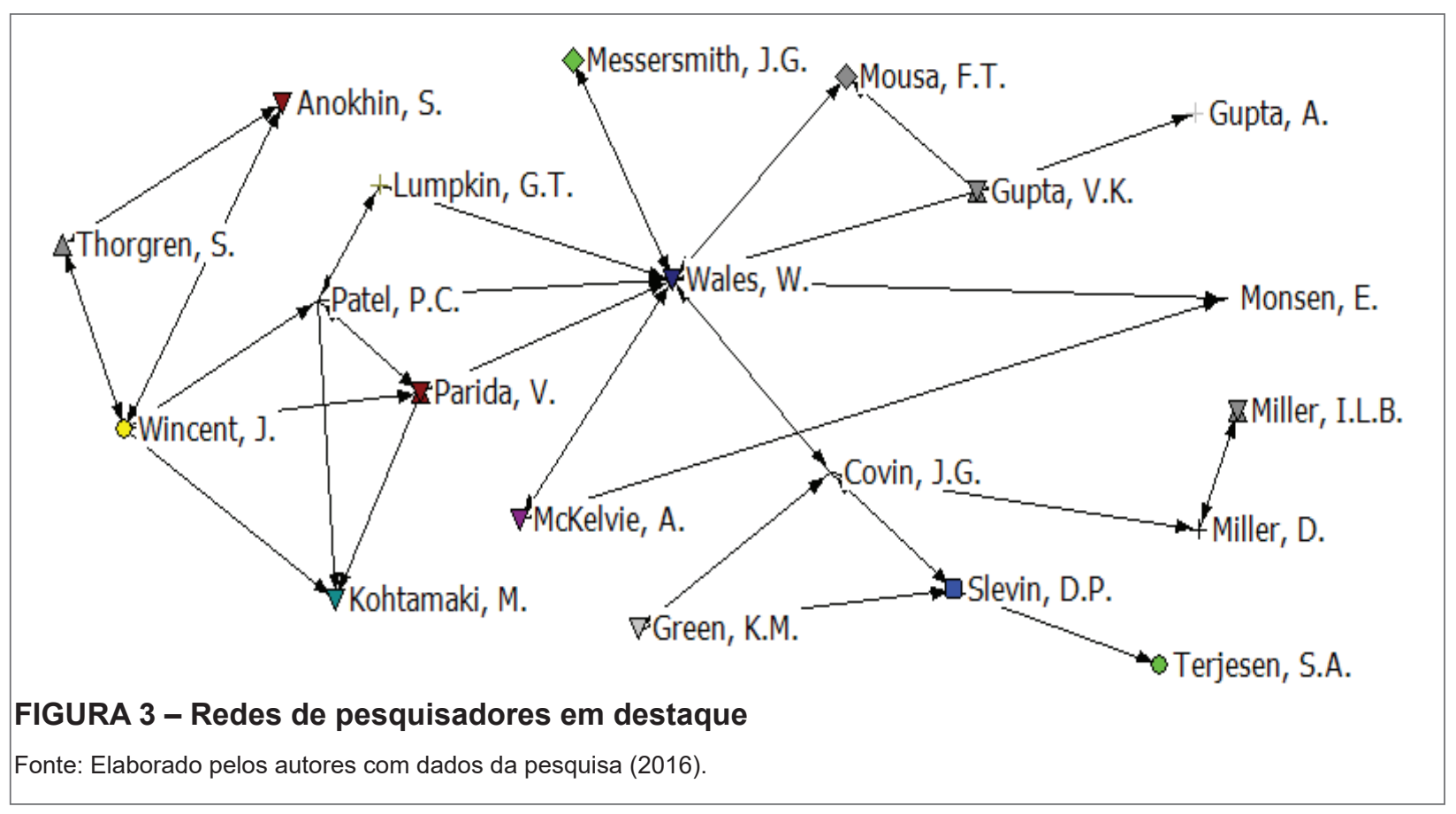




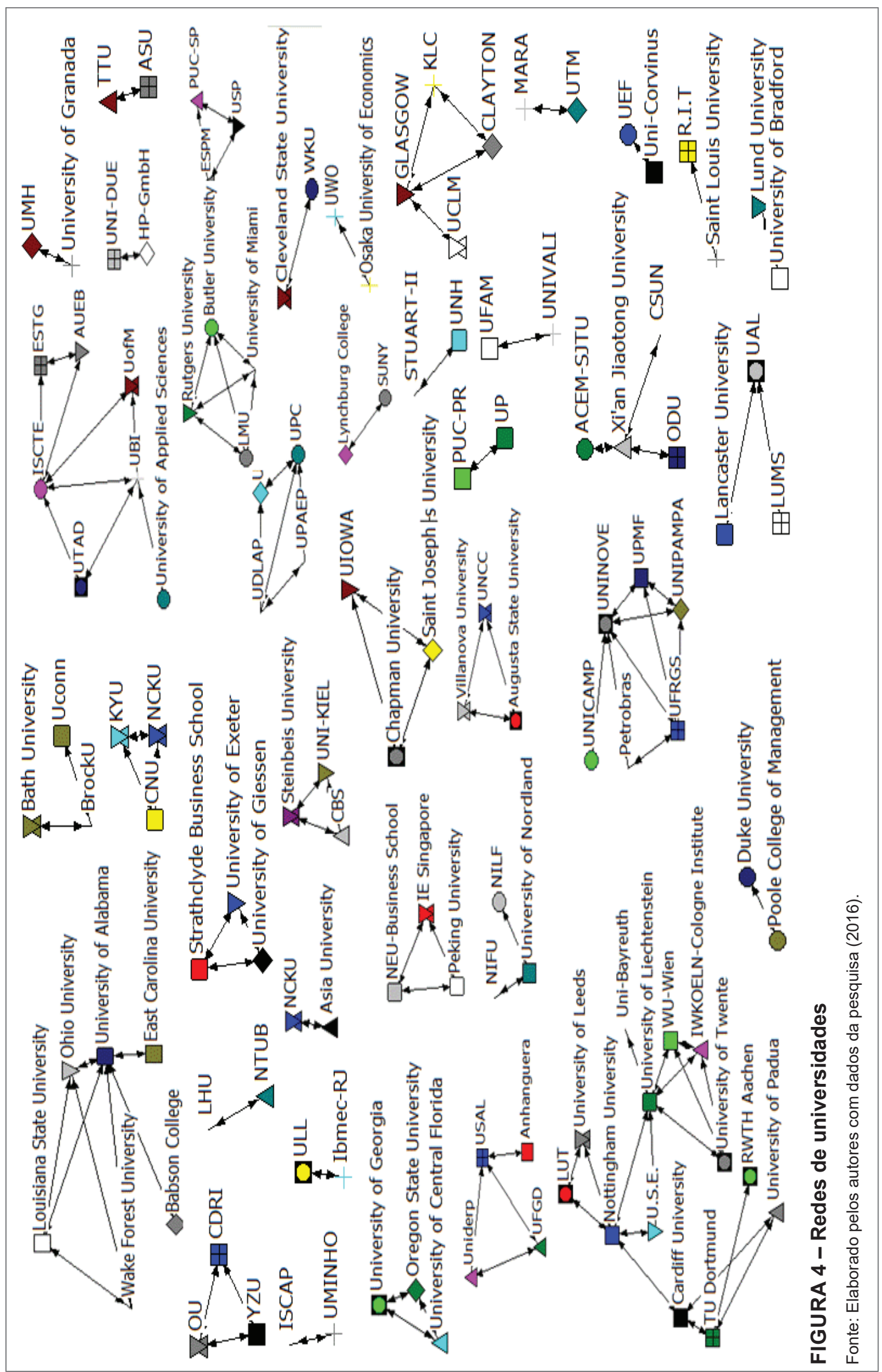




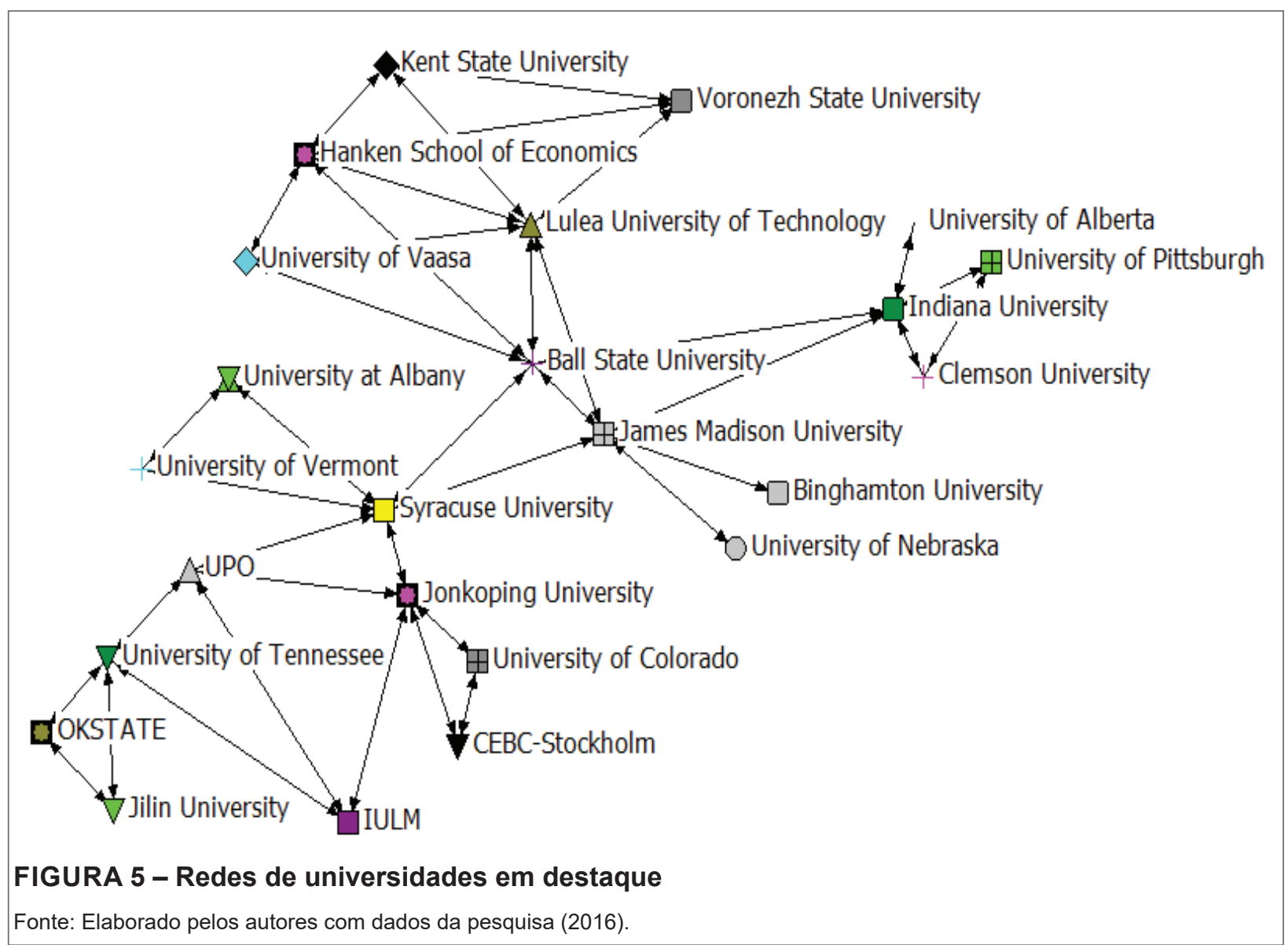

considerou-se a análise das referências dos artigos. Dessa maneira, verificou-se que o pesquisador Jeff G. Covin foi citado 425 vezes nos trabalhos. Por outro lado, o trabaIho destacado em números de citações foi "Clarifying the entrepreneurial orientation construct and linking it to performance", da autoria de Lumpkin e Dess, e publicado no periódico Academy of Management Review, em 1996, citado 69 vezes. No Quadro 4 , é possível verificar a relação com os 10 autores mais citados, bem como os trabaIhos relacionados a este pesquisador, com maior evidência em termos de quantidade de citações, e o quantitativo de menções dos mesmos.

Visando a ampliar outros estudos, como o desenvolvido por Martens; Freitas e Andres (20I I), realizou-se a identificação das dimensões utilizadas pelos pesquisadores para o desenvolvimento das suas pesquisas. Observou-se que 77 pesquisas $(68,75 \%)$ estão estruturadas com base nas dimensões: inovatividade; proatividade e assunção de riscos. Outras 27 pesquisas $(24,10 \%)$, nas dimensões: inovatividade; proatividade; assunção de riscos, autonomia e agressividade competitiva.

Observou-se, ainda, que duas (2) pesquisas $(1,78 \%)$ valeram-se exclusivamente das dimensões proatividade e assunção de riscos, enquanto outras seis (6) pesquisas $(5,35 \%)$ utilizaram-se de diferentes abordagens. Nessa perspectiva, verificam-se as pesquisas de: i) Jambulingam, Kathuria e Doucette (2005) que utilizaram as dimensões inovatividade, proatividade, assunção de riscos, autonomia, agressividade compe- 
QUADRO 4 - Citações de autores e trabalhos

\begin{tabular}{|c|c|c|c|}
\hline AUTOR & CIT. & TRABALHO COM MAIOR NÚMERO DE CITAÇÕES & CIT. \\
\hline COVIN, J.G & 425 & $\begin{array}{l}\text { COVIN, J. G.; SLEVIN, D. P. Strategic management of small firms in hostile and benign } \\
\text { environments. Strategic Management Journal, [S. I.], n. 10, p. } 75-87,1989 \text {. }\end{array}$ & 59 \\
\hline LUMPKIN, G.T & 312 & $\begin{array}{l}\text { LUMPKIN, G.; DESS, G. Clarifying the entrepreneurial orientation construct and linking it to } \\
\text { performance. The Academy of Management Review, [S. I.], v.21, n.1, p. 135-172, } 1996 .\end{array}$ & 69 \\
\hline SLEVIN, D.P & 261 & $\begin{array}{l}\text { SLEVIN, D. P.; COVIN, J. G. Juggling entrepreneurial style and organizational structure. } \\
\text { Sloan Management Review, [S. I.], v.31, n.2, p. } 43-53,1990 .\end{array}$ & 3 \\
\hline DESS, G.G & 254 & $\begin{array}{l}\text { DESS, G.G., LUMPKIN, G.T.; COVIN, J.G. 'Entrepreneurial strategy making and firm per- } \\
\text { formance: tests of contingency and configurational models'. Strategic Management Jour- } \\
\text { nal, [S. I.], v. } 18 \text {, n. 9, p. } 677-695,1997 \text {. }\end{array}$ & 13 \\
\hline MILLER, D & 243 & $\begin{array}{l}\text { MILLER, D. The correlates of entrepreneurship in three types of firms. Management. } \\
\text { Science, v. } 27, \text { n. } 7, \text { p. } 770-791,1983 .\end{array}$ & 61 \\
\hline WIKLUND, J. & 239 & $\begin{array}{l}\text { WIKLUND, J.; SHEPHERD, D. Entrepreneurial orientation and small business performance: } \\
\text { A configurational approach. Journal of Business Venturing, [S. I.], v. 20, p. 71-91, } 2005 .\end{array}$ & 36 \\
\hline ZAHRA, S.A & 216 & $\begin{array}{l}\text { ZAHRA, S. A.; COVIN, J.G. Contextual influences on the corporate entrepreneurship-per- } \\
\text { formance relationship: A longitudinal analysis. Journal of Business Venturing, [S. I.], } \\
\text { v. } 10 \text {, p. } 43-58,1995 \text {. }\end{array}$ & 23 \\
\hline SHEPHERD, D & 136 & $\begin{array}{l}\text { SHEPHERD, D.A.; COVIN, J.G.; KURATKO, D.F. 'Project failure from corporate entrepre- } \\
\text { neurship: managing the grief process', Journal of Business Venturing, [S. I.], v. } 24, \text { n. } 6 \text {, } \\
\text { p. } 588-600,2009 \text {. }\end{array}$ & 3 \\
\hline IRELAND, R.D & 88 & $\begin{array}{l}\text { IRELAND, R.; HITT, M.; SIRMON, D. "A model of strategic entrepreneurship: the construct } \\
\text { and its dimensions", Journal of Management, [S. I.], v. 29, n. 6, p. 963-989, } 2003 .\end{array}$ & 15 \\
\hline HITT, M.A & 81 & $\begin{array}{l}\text { HITT, M. A.; IRELAND, R. D.; CAMP, S. M.; SEXTON, D. L. Strategic entrepreneurship: } \\
\text { Entrepreneurial strategies for wealth creation. Strategic Management Journal, [S. I.], v.22, } \\
\text { p. } 479-492,2001 \text {. }\end{array}$ & 6 \\
\hline
\end{tabular}

Fonte: Elaborado pelos autores com dados da pesquisa (2016).

titiva e motivação; ii) Walter, Auer e Ritter (2006), com as dimensões: inovatividade, proatividade, assunção de riscos e autonomia; iii) Tajeddini (20l0), com as dimensões: inovatividade, proatividade, assunção de riscos e atitude em relação a processos de planejamento estratégico; iv) Home (20I I), com as dimensões: inovatividade, proatividade, assunção de riscos e orientação para o cliente; v) Franco e Haase (20/3), com as dimensões: inovatividade, proatividade, assunção de riscos e capacidade coletiva; e vi) Gutiérrez, Moreno e Tejada (20I5) apenas com a dimensão proatividade. Tais informações, de maneira detalhada, podem ser observadas no Quadro 5.

Observou-se que alguns artigos ex- põem os instrumentos de pesquisa que foram utilizados e, portanto, legitimados por meio da sua aplicação. Assim, destaca-se que os trabalhos de: Green, Covin e Slevin (2008); Gimenez e Gimenez (2009); Pearce, Fritz e Davis (20I0); George e Marino (20II); Bojica, Arroyo e Fuentes (20I2); Chen, Li e Evans (20I2); Wales, Gupta e Mousa (20I3); Murimbika e Urban (20I4); Wolfe e Shepherd (20I5); Gupta e Gupta (20I5), que apresentam tal informações. Este apontamento tem relevância quando do desenvolvimento de novas pesquisas, ou replicação de alguma, com foco distinto, em que seja necessário identificar instrumentos/questionários/roteiros para que isso ocorra. 
QUADRO 5 - Dimensões pesquisadas

\begin{tabular}{|c|c|}
\hline AUTORES & DIMENSÕES \\
\hline $\begin{array}{l}\text { Anderson e Eshima (2013); Bojica, Arroyo e Fuentes (2012); Bojica, Fuentes e Gras (2011); Bouncken } \\
\text { et al. (2014); Brouthers, Nakos e Dimitratos (2014); Campos et al. (2015); Chen, Li e Evans (2012); } \\
\text { Chien (2014); Clausen e Korneliussen (2012); Clercq, Dimov e Thongpapanl (2010); Clercq, Dimov e } \\
\text { Thongpapanl (2013); Covin e Miller (2014); Dada e Watson (2013); Dada e Watson (2013); Dai et al. } \\
\text { (2013); Davis (2011); Doorn et al. (2013); Engelena et al. (2014); Escobar, Lizote e Verdinelli (2012); } \\
\text { Fernandes e Santos (2008); Ferreira et al. (2014); Garcia (2010); George (2011); George e Marino } \\
\text { (2011); Gimenez e Gimenez (2009); Green, Covin e Slevin (2008); Gupta e Gupta (2015); Harms } \\
\text { (2010); Ibeh (2004); Javalgi e Todd (2011); Jiang et al. (2014); Junior, Borini e Guevara (2009); Keh, } \\
\text { Nguyen e Ng (2007); Kirkman (2013); Kollmann e Christofor (2014); Kollmann e Stockmann (2014); } \\
\text { Kraus et al. (2012); Kreiser (2011); Li e Liao (2010); Li, Liu e Liu (2011); Lisboa, Skarmeas e Lages } \\
\text { (2011); Luño, Cabrera e Wiklund (2011); Mello et al. (2006); Miller e Miller (2011); Monteiro, Soares e } \\
\text { Rua (2013); Morris, Webb e Franklin (2011); Mousa e Wales (2012); Murimbika e Urban (2014); Neto } \\
\text { et al. (2013); Neto et al. (2013);Ortega et al. (2013); Patel et al. (2014); Perlines (2014); Reijonen } \\
\text { et al. (2015); Ripollés e Blesa (2006); Roxas e Chadee (2013); Runyan et al. (2012); Sciascia et al. } \\
\text { (2014); Sciascia, Mazzola e Chirico (2013); Simsek, Heavey e Veiga (2010); Slevin e Terjesen (2011); } \\
\text { Soininen et al. (2012); Spillecke e Brettel (2012); Tajeddini, Elg e Trueman (2013); Talebi, Rezazadeh } \\
\text { e Najmabadi (2015); Tang e Tang (2012); Tijssen (2006); Tuan (2014); Veidal e Korneliussen (2013); } \\
\text { Villaverde, Ortega e Canales (2013); Wales e Messersmith (2013); Wales, Parida e Patel (2013); } \\
\text { Wales, Patel e Lumpkin (2013); Wiklund e Shepherd (2003/2005); Wincent, Thorgren e Anokhin } \\
\text { (2014); Zainol (2012) }\end{array}$ & $\begin{array}{c}\text { Inovatividade } \\
\text { Proatividade } \\
\text { Assunção de Riscos }\end{array}$ \\
\hline $\begin{array}{l}\text { Arshad et al. (2014); Balodi (2014); Barreto e Nassif (2014); Boso, Story e Cadogan (2013); Campos, } \\
\text { La Parra e Parellada (2012); Certo, Moss e Short (2009); Chang et al. (2007); Covin e Wales (2012); } \\
\text { Freitas et al. (2012); Hughes e Morgan (2007); Kollmann, Christofor e Kuckertz (2007); Lechner e } \\
\text { Gudmundsson (2014); Li et al. (2008); Li, Huang e Tsai (2009); Martens, Freitas e Andres (2011); } \\
\text { Neubaum, Mitchell e Schminke (2004); Pearce, Fritz e Davis (2010); Rosenbusch, Rauch e Bausch } \\
\text { (2013); Saeed, Yousafzai e Engelena (2014); Schiavone (2007); Silva, Gomes e Correia (2009); Voss, } \\
\text { Voss e Moorman (2005); Wales, Gupta e Mousa (2013); Wales, Monsen e McKelvie (2011); Wolfe e } \\
\text { Shepherd D. (2015) (2015); Wu, Chang e Chen (2008); Zhao et al. (2009) }\end{array}$ & $\begin{array}{l}\text { Inovatividade } \\
\text { Proatividade } \\
\text { Assunção de Riscos } \\
\text { Autonomia } \\
\text { Agressividade } \\
\text { Competitiva }\end{array}$ \\
\hline Avlonitis e Salavou (2007); Kreiser (2010) & $\begin{array}{c}\text { Proatividade } \\
\text { Assunção de Riscos }\end{array}$ \\
\hline
\end{tabular}

Fonte: Elaborado pelos autores com dados da pesquisa (2016).

\section{CONSIDERAÇÕES FINAIS}

presente estudo buscou realizar uma análise bibliométrica em artigos científicos nacionais e internacionais, no campo do conhecimento da orientação empreendedora, publicados nas principais revistas científicas. Foram identificados I I 2 artigos nas bases Ebscohot, Periódicos Capes, ProQuest e Spell, envolvendo o período de 2003 a 2015. A grande maioria dos artigos foi publicada em estratos AI e A2, com fator de impacto 3.144, demonstrando a alta qualidade desses estudos sobre OE.

O tema da orientação empreendedora está evoluindo ao longo dos últimos 12 anos, com picos de crescimento nos anos de 2013 a 2014 . Os II 2 artigos publicados estão distribuídos em 54 periódicos, sendo nacionais apenas 12 deles, o que indica que a pesquisa sobre orientação empreendedora ainda está incipiente no contexto brasileiro, mas com uma expectativa de evolução do tema em pesquisas futuras. Os países que mais publicaram sobre o tema foram Estados Unidos e o Reino Unido.

O estudo revelou um total de 250 autores na amostra, evidenciando, por parte de alguns autores, uma continuidade de pesquisas sobre o tema e novas ligações com diferentes pesquisadores, como é possível visualizar na rede de autores criada através dos artigos analisados. Com relação aos construtos, uma análise por meio da repetição destaca o construto desempe- 
nho organizacional como o mais relacionado com a OE. Com relação aos setores estudados, em geral, têm sido desenvolvidas pesquisas com foco em empresas de diversos setores. Os resultados também demonstram que o setor tecnológico é alvo frequente de pesquisas relacionadas com a $O E$, juntamente com micro e pequenas empresas. A orientação empreendedora vem sendo também alvo de pesquisas e testes sobre desempenho nas incubadoras de empresas, visto que essas entidades têm por objetivo apoiar empresas que estão no ciclo inicial de vida.

Este estudo contribui tanto para o meio acadêmico como para a prática organizacional. No campo acadêmico, pode ser usado como direcionador de fontes de pesquisas, uma vez que mapeia a produção científica nacional e internacional em re- vistas de alto impacto. Também contribui para identificação dos autores e suas ligações com os demais estudiosos do tema. No âmbito da prática organizacional, os interessados sobre o desdobramento do tema OE no ambiente organizacional podem encontrar, na amostra, fontes de pesquisas para análises de casos já aplicados em um contexto empresarial.

O estudo possui limitações, devido ao fato de não esgotar as possibilidades da existência de pesquisas sobre $\mathrm{OE}$ em bases de teses e dissertações, limitando os resultados deste estudo às bases pesquisadas. Para pesquisas futuras, sugere-se, portanto, ampliar o foco de pesquisa em mais bases de dados que contemplem periódicos, anais de eventos, teses e dissertações. Também é proposto que os estudos futuros mensurem a dimensão de redes de negócios. 


\section{REFERÊNCIAS}

BASILE, A. Entrepreneurial orientation in smes: risk-taking to entering international markets. Far East Journal of Psychology and Business, [S. I.], v. 7, n. 2, P. I-I7, 2012.

BOUCHARD, V. Corporate entrepreneurship: lessons from the field, blind spots and beyond. European Entrepreneurial Learning: Cahiers de Recherche, [S. I.], n. 2002/08, 2002.

BUSS, D. M. Selection, evocation, and manipulation. Journal of Personality \& Social Psychology, [S. I.], v. 53, n. 6, p. I2|4- |22।, 1987.

CHEN, M. J.; HAMBRICK, D. C. Speed stealth and selective attack: how small firms differ from large firms in competitive behavior. The Academy of Management Journal, New York, v. 38, n. 32, p. 453-482, 1995.

CORIAT, B. Pensar pelo avesso: o modelo japonês de trabalho e organização. Rio de Janeiro: Revan/UFRJ, 1994.

COVIN, J. G.; MILLER, D. International entrepreneurial orientation: conceptual considerations, research themes, measurement issues, and future research directions. Entrepreneurship Theory and Practice, [S. I.], v. 38, n. I, p. II44, 2014.

COVIN, J. G.; COVIN, T. J. Competitive aggressiveness, environmental context, and small firm performance. Entrepreneurship: Theory \& Practice, [S. I.], v. I4, n. 4, p. 35-50, 1990.

COVIN, J. G.; SLEVIN, D. P. Strategic management of small firms in hostile and benign environments. Strategic Management Journal, [S. I.], v. I0, n. I, p. 75-87, 1989.

COVIN, J. G.; GREEN, K. M.; SLEVIN, D. P. Strategic Process Effects on the Entrepreneurial OrientationSales Growth Rate Relationship. Entrepreneurship: Theory \& Practice, [S. I.], v. 30, n. I, p. 578I, 2006.

COVIN, J. G.; SLEVIN, D. P.A conceptual model of entrepreneurship as firm behavior. Entrepreneurship: Theory \& Practice, [S. I.], v. I6, n. I, p. 7-25, I99I.

COVIN, J.; WALES, W. The measurement of entrepreneurial orientation. Entrepreneurship: Theory \& Practice, v. 36, n. 4, p. 677-702, 2012.

DESS, G. G.; LUMPKIN, G.T.; MCGEE, J. E. Linking corporate entrepreneurship to strategy, structure, and process: suggested research directions. Entrepreneurship: Theory \& Practice, [S. I.], v. 23, n. 3, p. 85-102, 1999.

DESS, G. G.; LUMPKIN, G.T.The role of entrepreneurial orientation in stimulating effective corporate entrepreneurship. The Academy of Management Executive, [S. I.], v. 19, n. I, p. 147-156, 2005.

FILION, L. J. O planejamento do seu sistema de aprendizagem empresarial: identifique uma visão e avalie o seu sistema de relações. Revista de Administração de Empresas, [S. I.], v. 3 I, n. 3, p. 637I, 199I.

GIL, A. C. Métodos e técnicas de pesquisa social. 5. ed. São Paulo: Atlas, 2008. p. 200.

GREEN, K. M.; COVIN, J. G.; SLEVIN, D. P. Exploring the relationship between strategic reactiveness and entrepreneurial orientation: The role of structure-style fit. Journal of Business Venturing, [S. I.], v. 23, n. 3, p. 356-383, 2008.

GUTH, W. D.; GINSBERG, A. Guest editors' introduction: corporate entrepreneurship. Strategic Management Journal, [S. I.], v. I I, n. 4, p. 5-15, 1990.

HAIR, J. J. F.; BABIN, B.; MONEY, A. H.; SAMOUEL, P. Fundamentos de métodos de pesquisa em administração. Porto Alegre: Bookman, 2005. p. 47I.

HITT, M. A.; NIXON, R.; HOSKISSON, R.; KOCHHAR, R. Corporate entrepreneurship and crossfunctional fertilization: Activation, process and disintegration of a new product design team. Entrepreneurship: Theory \& Practice, [S. I.], v. 23, n.3, p. I45-168, 1999.

HUGHES, M.; MORGAN, R. E. Deconstructing the relationship between entrepreneurial orientation and business performance at the embryonic stage of firm growth. Industrial Marketing Management, [S. I.], v. 36, n. 5, p. 65 I-66I, 2007.

HUGGINS, R.;THOMPSON, P. Entrepreneurship, innovation and regional growth: a network theory. Small Business Economics, [S. I.], v. 45, n. I, p. I03-I 28, 2015.

JENSSEN, J. I.; NYBAKK, E. Inter-organizational innovation promoters in small, knowledge intensive firms. International Journal of Innovation Management, [S. I.], v. I3, n.3, p. 44I-466, 2009.

JORDAN, J. D.; MELOUK, S. H.; PERRY, M. B. Optimizing football game play calling. Journal of Quantitative Analysis in Sports, [S.I.], v. 5, n. 2, p. I-34, 2009.

KHANDWALLA, P. N. Some top management styles, their context and performance. Organization \& Administrative Sciences, [S. I.], v. 7, p. 2 I-5 I, I976-1977.

KNIGHT, G. A. Cross-cultural reliability and validity of a scale to 
measure firm entrepreneurial orientation, Journal of Business Venturing, v. 12, p. 213-25, 1997. KRAUS, S.; RIGTERING, C.; HUGHES, M.; HOSMAN, V. Entrepreneurial orientation and the business performance of SMEs: a quantitative study from the $\mathrm{Ne}$ therlands. Review of Managerial Science, [S. I.], v. 6, n. 2, p. |6I-|82, 2012.

KREISER, P. M.; MARINO, L. D.; WEAVER, K. M. Assessing the psychometric properties of the entrepreneurial orientation scale: a multi-country analysis. Entrepreneurship: Theory \& Practice, [S. I.], v. 26, n. 4, p. I-94, 2002.

LAZZAROTTI, F.; SILVEIRA, A. L. T.; CARVALHO, C. E.; ROSSETTO, C. R.; SYCHOSKI, J. C. Orientação empreendedora: um estudo das dimensões e sua relação com desempenho em empresas graduadas. RAC - Revista de Administração Contemporânea, [S. I.], v. 19, n. 6, p. 673-695, 2015.

LEE, S. M.; PETERSON, S. J. Culture, Entrepreneurial orientation, and global competitiveness. Journal of World Business, [S. I.], v. 35, n. 4, p. 40l-4l 6, 2000.

LEITE, E. Empreendedorismo, inovação e incubação de empresas: lei de inovação. Recife: Bargago, 2006.

LUMPKIN, G.T; DESS, G. G. Clarifying the entrepreneurial orientation construct and linking it to performance. Academy of Management Review, [S. I.], v. 2I, P. |35-172, 1996.

LUMPKIN, G. T.; DESS, G. G. Linking two dimensions of entrepreneurial orientation to firm performance: the moderating role of environment and industry life cycle. Journal of Business Venturing, Georgia, [S. I.], v. 16, n. 5, p. 42945I, 200 I.
LUMPKIN, G. T.; COGLISER, C. C.; SCHNEIDER, D. R. Understanding and measuring autonomy: An entrepreneurial orientation perspective. Entrepreneurship: Theory \& Practice, [S. I.], v. 33, n. I, p. 47-69, 2009.

MACMILLAN, I. C.; DAY, D. L. Corporate ventures into industrial markets: dynamics of aggressive entry. Journal of Bussiness Venturing, [S. I.], v. 2, p. 29-39, 1987.

MARTENS, C. D. P.; FREITAS, H.; ANDRES, R. Desenvolvimento da orientação empreendedora em empresas de software: proposições preliminares. Revista Eletrônica de Administração, [S. I.], v. 69, n. 2, p. 424-450, 20 I I.

MCDOUGALL, P.; OVIATT, B. International entrepreneurship: the intersection of two research paths. Academy of Management Journal, [S. I.], v. 43, n. 5, p. $902-$ 906, 2000.

MCCLELLAND, D. C. A sociedade competitiva: realização e progresso social. Rio de Janeiro: Expressão e Cultura, 1972.

MELLO, S. C. B. et al. Maturidade empreendedora e expertise em compasso de inovação e risco: um estudo em empresas de base tecnológica. In: ENCONTRO DA ASSOCIAÇÃO NACIONAL DE PÓS-GRADUAÇÃO E PESQUISA EM ADMINISTRAÇÃO - ANPAD, 28., 2004, Curitiba. Anais... Rio de Janeiro: ANPAD, 2004.

MELLO, S. C. B.; LEÃO, A. L. M. S. Compreendendo a orientação empreendedora de empresas de alta tecnologia. In: SOUZA, E. C. L.; GUIMARÃES, T.A. (Org.). Empreendedorismo além do plano de negócios. São Paulo:Atlas, 2005. p. I62-178.

MESSEGHEM, K. Strategic Entrepre- neurship and Managerial Activities in SMEs. International Small Business Journal, [S. I.], v. 21 , n. 2, p. 197-2 I2, 2003.

MILLER, D.; FRIESEN, P. H.Archetypes of strategy formulation. Management Science, [S. I.], v. 24, n. 9, p. 92I-933, 1978.

MILLER, D. The correlates of entrepreneurship in three types of firms. Management Science, [S. I.], v. 29, n. 7, p. 770-79I, 1983.

MILLER, D.; FRIESEN, P. H. Innovation in conservative and entrepreneurial firms: two models of strategic momentum. Strategic Management Journal, [S. I.], v. 3, n. I, p. I-26, 1982.

MILLER, D. Miller (1983) revisited: a reflection on EO research and some suggestions for the future. Entrepreneurship Theory and Practice, [S. I.], v. 35, n. 5, p. 873-894, 2011.

MILES, M. P.; COVIN, J. G.; HEELEY, M. B. The Relationship between Environmental dynamism and Small Firm Structure, Strategy, and Performance. Journal of Marketing Theory and Practice, [S. I.], v. 8, n. 2, p. 63-78, 2000.

MILES, R. E.; SNOW, C. C. Organizational strategy, structure, and process. Palo Alto, CA: Stanford University Press, 1978.

MINTZBERG, H. Strategy-making in three modes. California Management Review, [S. I.], v. I6, n. 2, p. 44-53, 1973.

MORRIS, M. H.; LEWIS, P. S.; SEXTON, D. L. Reconceptualizing entrepreneurship: an input-output perspective. SAM Advanced Management Journal, [S. I.], v. 59, n. I, p. 2 I-3 I, I 994.

OBERG, C.; GRUNDSTRÖM, C. Challenges and opportunities in innovative firms' network development. International Journal of Innovation Management, 
[S. I.], v. I3, n. 4, p. 593-6/3, 2009.

PAIVA JR., F. G. de; FERNANDES, N.

C. M.; ALMEIDA, L. F. L. A competência de relacionamento contribuindo para o desenvolvimento de capital social da empresa de base tecnológica. Revista de Negócios, [S. I.], v. I 5, n. I, p. I I-28, 2010.

RICHARD, O. C. et al. Cultural diversity in management, firm performance, and the moderating role of entrepreneurial orientation dimensions. Academy of Management Journal, v. 47, n. 2, p. 255-266, 2004.

SCHUMPETER, J.A. Capitalism, socialism, and democracy. New York: Harper \& Brothers, 1942.

SILVA, E. L.; MENEZES E. M. Metodologia da pesquisa e elaboração de dissertação. 4. ed. Florianópolis: UFSC, 2005.

SILVEIRA-MARTINS, E.; VAZ, C. S. Orientação empreendedora e sua associação com as capacidades dinâmicas: um estudo em agroindústrias gaúchas. Revista em Agronegócios e Meio Ambiente, [S. I.], 2016. No prelo.

SILVEIRA-MARTINS, E.; VAZ, C. S. Orientação empreendedora associada ao desempenho: uma análise de agroindústrias do RS. In: CONGRESSO INTERNACIONAL DE ADMINISTRAÇÃO, 2015, Ponta Grossa. Anais... Ponta Grossa: ADMPG, 2015.

SHENG, $H$. H. Modelos de financiamento baseados em relações pes- soais: experiência de empreendedores chineses no Brasil. Revista de Administração Contemporânea, [S. I.], v. I2, n. 3, p. 74I76I, 2008.

STEVENSON, H. H.; JARILLO, J. C. A paradigm of entrepreneurship: entrepreneurial management. Strategic Management Journal, Chichester, [S. I.], v. I I, n. 5, p. 17-27, 1990.

TANG, J.; TANG, Z.; ZHANG, Y.; LI, $Q$. The impact of entrepreneurial orientation and ownership type on firm performance in the emerging region of China. Journal of Developmental Entrepreneurship, [S. I.], v. 12, n. 4, p. 383-397, 2007.

VENKATRAMAN, N. Strategic orientation of business enterprises: the construct, dimensionality and measurement. Management Sciences, [S. I.], v. 35, n. 8, p. 94I962, 1989.

WANG, C. L. Entrepreneurial Orientation, Learning Orientation, and Firm Performance. Entrepreneurship: Theory \& Practice, [S. I.], v. 32, n. 4, p. 635-657, 2008.

WIKLUND, J. Entrepreneurial orientation as predictor of performance and entrepreneurial behaviour in small firms - longitudinal evidence. Frontiers of Entrepreneurship Research 1998, Disponível em: $<$ http://www.babson.edu/entrep/ fer/papers98/index98/index98. html>. Acesso em: 16 dez. 2015.
WIKLUND, J.The sustainability of the entrepreneurial orientation-performance relationship. Entrepreneurship: Theory \& Practice, [S. I.], v. 24, n. I, p. 37-48, Fall 1999.

WIKLUND, J.; SHEPHERD, D. Entrepreneurial orientation and small business performance: a configurational approach. Journal of Business Venturing, [S. I.], v. 20, n. I, p. 7I-9I, 2005.

ZAHRA, S. A. Environment, corporate entrepreneurship and financial performance: A taxonomical approach. Journal of Business Venturing, [S. I.], v. 8, p. 31 9-340, 1993.

ZAHRA, S.A; COVIN, J. G. Contextual influences on the corporate entrepreneurship-performance relationship: A longitudinal analysis. Journal of Business Venturing, [S. I.], v. 10, p. 43-58, 1995.

ZHENG ZHOU, K.;YIM, C. K.;TSE, D. $K$. The effects of strategic orientations on technology- and market -based breakthrough innovations. Journal of Marketing, [S. I.], v. 69, n. 2, p. 42-60, 2005.

ZOSCHKE, A. C. K.; LIMA, E. O. Marketing empreendedor e redes de relação: um estudo sobre micro, pequenas e médias empresas. In: ENCONTRO DA ASSOCIAÇÃO NACIONAL DE PÓSGRADUAÇÃO E PESQUISA EM ADMINISTRAÇÃO, 30., 2006, Salvador. Anais... Rio de Janeiro: ANPAD, 2006. 